\title{
Volatiles play an important role in the attractiveness of food for trapping the stored grain pests Oryzaephilus surinamensis L. (Coleoptera: Silvanidae)
}

\author{
Maidinai Sabier 1,, , Jirui Wang 1, $\$$, Xia Wang 1,, Jiande Jin ${ }^{2}$, Zhunjing Wang ${ }^{1}$, Zhihong Liao ${ }^{1}$, Bo Shen ${ }^{3}$, Lu Jin ${ }^{4}$, \\ Jianyu Deng ${ }^{1}$, Xingquan Liu ${ }^{1, *}$ and Guoxin Zhou ${ }^{1, *}$
}

1 Key Laboratory for Quality Improvement of Agriculture Products of Zhejiang Province, Zhejiang A\&F University, Hangzhou 311300, China;

2 Zhejiang Grain Reserves Management Co. Ltd, Hangzhou, Zhejiang 310000, China

3 Zhejiang Zhongsui Industrial Co. Ltd, Xiaoshan 311200, Zhejiang, China

4 Zhejiang Yuezhou Warehousing Industry Co., Ltd, Shaoxing 312000, Zhejiang, China

* Correspondence: liuxq@zafu.edu.cn; gxzhou@zafu.edu.cn

Simple Summary: The Oryzaephilus surinamensis L. (Coleoptera: Silvanidae), is widely distributed all over the world, this beetle causes serious damage to stored products. Much attention has been paid to use food attraction or food volatile as a non-pollution method to achieve pest management. However, in this study, six most attractive food to O. surinamensis were selected among thirty eight food. Furthermore, the food mixture M17 with the best attractiveness were selected among the eighteen food mixtures combined by these six foods at different ratio. Subsequently food mixture M17 were tested in actual barn and compared with commercial attractant. We collected the volatile from food mixture, the volatile compounds attractive to this beetle also. We identified six electrophysiologically active compounds responsible for the attraction of O. surinamensis, among the six chemically identified compounds, nonanal, dodecane, tridecaneand $\beta$-caryophyllene significantly attracted O. surinamensis when tested individually in behavioral assays. Blend of six chemicals according to food volatile concentration was most attractive to the beetles. The findings of this study reveal that food mixture M17 and food volatile can be potentially used for development of effective attractants for management of $O$. surinamensis.

\begin{abstract}
Insects pests of stored products can cause serious damage to stored grains and have threatened global food security for centuries. It is clear that new approaches and strategies are required including insects population monitoring technology and green control measures when insect resistance to pesticides is increasing worldwide, and increasing awareness of environmental stresses and human health concerns.
\end{abstract}

Oryzaephilus surinamensis L. (Coleoptera: Silvanidae) (ORSU) is a major worldwide pest of stored products. In this study, six types of foods that require storage (oatmeal, figs, sucrose, hawthorn, cashew, millet, and wolfberry) were selected from a total of 38 different food products as the most attractive to these beetles. The mixture (M17) from mixtures of these six individual foods at different ratios that was the most attractive to ORSU and its attractiveness varied at different population densities of insects and trapping rates were highest at an environmental temperature of 25 ${ }^{\circ} \mathrm{C}$. Interestingly, M17 remained effective as a trap bait for at least 40 days and also attracted other stored product insects (Tribolium castaneum, Cryptolestes ferrugineus, and Sitophilus oryzae).

M17 volatiles were found to be perceived by O. surinamensis, in which three of these, nonanal, dodecane, and $\beta$-caryophyllene were also behaviorally active; The chemical, tridecane, had no obvious EAG activity but was effective as a trap bait for O. surinamensis, and conversely, dibutyl phthalate (probably a contaminant), which had obvious EAG activity was not significantly attractive. 
Our results show that food volatiles play an essential role in attracting stored-product pests and suggest that specific food mixtures could be used as effective lures to trap the pests. The use of food-based attractants could be an effective and environmentally friendly part of integrated pest management programs as trapping and monitoring tools.

Keywords: Oryzaephilus surinamensis; food mixtures; field trapping; volatiles; antennal response;

\section{Introduction}

Pests have been harming natural resources, including trees, fruits, and other human foods, since before the rise of agriculture [1,2]. However, in addition to these insect pests in the field, a group of herbivorous insects, known as stored-product insects, began to appear as humans started to produce excess agricultural produce and store this as provisions over longer periods of time [2,3]. About a third of the total potential harvest of plant food crops are damaged or destroyed by pests during growth, harvest and storage [4]. Stored grain pests can cause major losses, and it is estimated that up to $9 \%$ stored grains in developed countries and $20 \%$ or more in developing countries can be lost through these pests [5]. A total of 1,663 known insect species have been recorded to damage post-harvest agricultural commodities and about a hundred are major, economically important pests [3]. How stored-product insects are to be effectively and safely controlled in order to decrease the losses of food during storage in warehouses is a huge challenge for humans, especially with the increasing human population.

In recent decades, because of its simplicity and effectiveness, chemical control, including fumigants and residual insecticides, has been the most common method to control stored product insects [6,7]. Unfortunately, because of the widespread use of pesticides, the environmental impact of these chemicals has become a significant problem, and resistance of the insect pests to the chemicals has also increased over the last five decades [8]. Resistance to fumigant insecticides in stored-product insects is now common [3,7]. In a global survey investigating resistance to the fumigant gas phosphine at 250 localities in 60 countries, six out of eight beetle species were reported to have developed resistance to the gas [7] and phosphine resistance has been reported in many types of insects including Oryzaephilus surinamensis (Silvanidae), Rhyzopertha dominica (Bostrichidae), Tribolium castaneum (Tenebrionidae) and Cryptolestes ferrugineus (Laemophloeidae) [9-11]. The most resistant $T$. castaneum population was found to be 119 -fold more resistant than the susceptible strain, and the most resistant $R$. dominica population was over 1,500-fold more resistant [12]. A different study, also in Oklahoma, detected resistance to phosphine in four out of 14 populations of $O$. surinamensis adults and nine out of 14 populations of eggs, with resistance frequencies between 2 to $100 \%$ [13]. Some stored-grain insect fumigants have been banned. Methyl bromide has been used globally since the 1930s as a quarantine treatment for plants and to control insects in buildings and commodities. Methyl bromine, however, was found to be an ozone-depleting substance, and the bulk of its consumption has been banned since 2005 under the Montreal Protocol [6]. Therefore, with the increasing resistance of the insect pests to chemicals, and with environmental protection in mind, it is necessary to find new chemicals or new alternative methods that can effectively control pests while leaving humans and the environment unharmed $[7,14,15]$.

In order to meet food safety and security needs for the growing world population, a finely-tuned IPM (integrated pest management) program was developed by the UN, combining chemical control, bio-rational methods, biological control $[3,5,15]$, and genetic approaches [16]. Technology to attract and trap stored product insects using pheromones and other semiochemicals, as well as food attractants, was developed and has been emphasized widely in granaries as a suitable sampling and control method as part of the IPM 
system $[3,5,17]$. The use of attractants can lead to earlier detection of infestations, can accurately detect insect population levels, and can also help managers to take reasonable control measures and minimize pest damage before any chemical residues are deposited in the environment or in the food products $[18,19]$. Much progress has been made in controlling stored-product insects through food attractants and pheromones [15,20]. Experiments using closely-spaced pheromone traps for moths including Plodia interpunctella, Ephestia spp., and other species in different warehouses of grain showed that traps attracting males and disrupting mating were able to significantly reduce the population density of P. interpunctella and Ephestia cautella in the second year of trap use [15,21]. Interestingly, another study showed that traps baited with agave tissue as well as pheromones were able to capture more Scyphophorus acupunctatus weevils (Coleoptera: Cuculionidae) than could traps baited with either pheromones or agave alone [22].

There has been significant research into food lures, and many products have been tested. There has been significant scientific interest in behaviors and mechanisms of responses of stored-product insects towards traps baited with food attractants [5]. As early as the 1980s it was reported that adult O. surinamensis beetles could be attracted in laboratory assays using Y-tube olfactometers baited with rolled oats and pentane extracts of oats [23]. A previous report suggested that the "secondary pests" O. surinamensis, T. castaneum and Tribolium confusum were primarily attracted to kernels which had been previously damaged by "primary pests" [24]. Results of experiments investigating the attraction of Lasioderma serricorne (F.) towards 11 stored products, demonstrated that tobacco, cocoa, soybean flour, black tea, and wheat flour significantly attracted the beetles [25]. Crawling insects Trogoderma granarium and O. surinamansis tend to be attracted to traps with food lures such as walnuts, oats or wheat germ oils [26]. Mee oil (Madhuca longifolia) and coconut (Cocos nucifera) oil are also able to attract T. castaneum adults under laboratory conditions [27]. Furthermore, food based attractants are commonly used to capture sawtoothed grain beetles, merchant grain beetles, rice weevils, granary weevils, and rusty grain beetles [28]. Several commercial attraction trap products have also appeared on the market, including the multi-species trap for stored-product pests Xlue MST, which consists of two specialist food lures and three pheromones, is advertised as being able to trap twelve different stored-product pest species, and which is widely used throughout the world (https://russellipm.com/).

The volatile chemicals in the food may play a role in determining the attractiveness of food baits, and food volatiles have been well studied as potential attractants for storedgrain pests [29,30]. A two-choice pitfall olfactometer has been used to examine the behavioral responses of granary weevils to twenty individual food volatiles, including aliphatic alcohols, aldehydes, ketones, and aromatics, showing that the beetles found eight of the tested compounds attractive, at at least one concentration [31]. Volatiles from kibbled carob have also been shown to attract three species, Sitophilus zeamais, Sitophilus oryzae, and Sitophilus granarius [32]. A great deal of literature also exists addressing the attractiveness of food volatiles to other pest species [33-36].

The stored-product insect Oryzaephilus surinamensis L. has achieved a worldwide distribution and is regarded as a major stored grain pest, and not only attacks stored grains and their products, but also poses a potential threat to public health as it can cause allergies in humans $[37,38]$. The presence of this insect causes global damage to grains and grain products with an estimated cost of seventy billion dollars annually [39].

In the present study, the relative attractiveness to O. surinamensis (ORSU) of thirtyeight different foods was estimated. A series of food mixtures was then designed, each with six selected foods, and the attractiveness of these mixtures was assessed both in the laboratory and in a large flat granary. The function of the food volatiles and bioactive compounds in those volatiles in attracting stored-product insects was also analyzed using both bioassays and electrophysiological methods. We found that some food mixtures, in- 
cluding the food mixture M17, are effective as trap attractants to ORSU, and several chemicals in the eluents of volatiles from food mixtures may play important roles in the attractiveness of foods to these beetles. 


\section{Materials and Methods}

\subsection{Materials}

\subsubsection{Insects}

Adult Oryzaephilus surinamensis L. (ORSU) beetles were collected from Yuezhou Provincial Grain Reserve Storage (Shaoxing, China). Four other insect species, Tribolium castaneum, Sitophilus oryzae, Cryptolestes ferrugineus, and Rhyzopertha dominica were collected from Zhongsui Provincial Grain Reserve Storage (Xiaoshan, China). The insect populations were then reared on a mixture of whole wheat flour, oatmeal and yeast (whole wheat flour : oatmeal : yeast $=6: 3: 1$ ), and grown in an incubator at $30 \pm 1{ }^{\circ} \mathrm{C}$ and $70 \%-75 \%$ relative humidity $(\mathrm{RH})$, in darkness [40]. Between 20-30 days after emergence, adult beetles of both sexes were collected held in centrifuge tubes without food for $24 \mathrm{~h}$ in darkness at $31^{\circ} \mathrm{C}$, before behavioral bioassays were conducted.

\subsubsection{Foods}

Thirty-eight types of foods, including oatmeal and dried figs, were chosen as potential attractants. These foods are listed in Table S1. All of these foods were purchased from a Wall-Mart supermarket, Lin'an district, Hangzhou, China. A series of food mixtures consisting of six foods (oatmeal, dried hawthorn, millet, sucrose, cashew, and dried fig) were assembled using an orthogonal design based on three weights of each food (Table $1)$.

\subsubsection{Chemicals and Instruments}

The chemicals nonanal $(>95 \%)$ and $\beta$-caryophyllene $(>95 \%)$ were purchased from Tokyo Chemical Industry Co., Ltd. Dodecane (>90\%), tridecane (99\%), 2,6-di-tert-butyl4-methylphenol (99.7\%), diisobutyl phthalate $(>99 \%)$, methyl palmitate $(>99 \%)$, and dibutyl phthalate $(>99.5 \%)$ were purchased from Sigma Aldrich (Shanghai, China) and PoraPak $^{\mathrm{TM}} \mathrm{Q}$ (80-100 mesh) from Waters Corporation (https://www.waters.com). Chemicals were diluted with dichloromethane to the appropriate concentrations for different bioassays.

The technical equipment used included a six-armed olfactometer apparatus (Sanaisi Scientific Instrument Co., Ltd. Jiangsu, China); a vacuum pump (DOA-P504-BN from Gast Manufacturing Company, USA; an electronic balance (PL2002, from Mettler Toledo Instruments Co., Ltd., Shanghai, China); an intelligent artificial climate incubator (RXZ, from Ningbo Jiangnan Instrument Factory, Zhejiang, China); and a GCMS-QP2010 Plus (Shimadzu Corporation, https://www.shimadzu.com.cn). Gas Chromatography-Electroantennographic Detection (GC-EAD) equipment consisted of GC-2010 Plus equipped with an HP-5 capillary column $(30 \mathrm{~m} \times 0.25 \mathrm{~mm}$ id, $0.25 \mu \mathrm{m}$ film thickness), a flame ionization detector (FID) from Shimadzu Corporation (https://www.shimadzu.com.cn) and an EAD unit from Syntech company (Germany).

\subsection{Determination of relative attractive activity of single food}

The six-armed olfactometer consisted of a glass cylinder (diameter $5 \mathrm{~cm}$, height 11.8 $\mathrm{cm}$ ). The bottom of the chamber had six arms (diameter $1.5 \mathrm{~cm}$, length $23 \mathrm{~cm}$ in length, with two arms extended at $45^{\circ}$ ), with a $50 \mathrm{~mL}$ pear-shaped flask connected to the end of each arm. For each experiment the flasks were prepared as follows: four of the flasks were each filled with $2.5 \mathrm{~g}$ of a single kind of attractant, one flask was filled with the same weight of flour for a standard control and one was left empty as a blank. 50 adult O. surinamensis beetles were placed in the center of the olfactometer cylinder. The olfactometer together with the insects was then placed in the climate incubator in the dark, and at $31 \pm$ $1{ }^{\circ} \mathrm{C}$ and $70 \% \mathrm{RH}$. After $24 \mathrm{~h}$, the number of insects preferring each food was counted. A beetle was deemed to have chosen a particular food if it had moved down the arm of the olfactometer by more than $5 \mathrm{~cm}$. The experiment was repeated three times and the relative attractiveness of each single food was calculated as the ratio of the average number of beetles preferring this food over other foods or flour. 


\subsection{Attractiveness of food mixtures in the lab}

To measure the effectiveness of the eighteen food mixtures, M1-M18, as trapping baits, a plastic box $(38 \mathrm{~cm} \times 26 \mathrm{~cm} \times 18.5 \mathrm{~cm})$ was filled with rice to a depth of about $13 \mathrm{~cm}$, and 200 adult insects were uniformly distributed throughout the box $2 \mathrm{~h}$ before the experiment. Twenty $50 \mathrm{~mL}$ type traps (diameter $3 \mathrm{~cm}$, length $11.5 \mathrm{~cm}$ ) with nine gaps (length $1.5 \mathrm{~cm}$, wide $0.2 \mathrm{~cm}$ ) (Figure S1) were evenly inserted in four rows and five columns into the rice, keeping the top gape circle of the trap (Figure S1 d) parallel with the rice surface. A food mixture was randomly assigned to eighteen of the twenty traps, and the other two traps were left empty as a control. The box was placed in the dark at $28 \pm 2{ }^{\circ} \mathrm{C}$ and $70 \%$ $\mathrm{RH}$ for $24 \mathrm{~h}$. After $24 \mathrm{~h}$, the number of insects in each tube was recorded and the attractiveness of each food mixture was calculated as the number of insects trapped in tube divided by the total number of insects in all the tubes. These experiments were repeated three times.

\subsection{Evaluation of the effect of temperature and insect density condition on the attractiveness of food mixture M17}

A plastic box $(24 \mathrm{~cm} \times 34 \mathrm{~cm} \times 18.5 \mathrm{~cm})$ was filled with rice to two thirds of the height of the box height. Two $50 \mathrm{~mL}$ type traps (diameter $3 \mathrm{~cm}$, height $11.5 \mathrm{~cm}$ ) were each baited with $7.6 \mathrm{~g}$ food mixture M17 as described above, or with nothing as a control. All the trap tubes were arranged in a ring, and adjacent tubes were kept $13 \mathrm{~cm}$ apart (Figure S2). Each tube was inserted into the rice so that the top gape circle of the trap was flush with the rice surface. 20 adults of $O$. surinamensis were uniformly distributed over the surface of the rice, and the box was placed in the dark, with $70 \% \mathrm{RH}$ at $28 \pm 2{ }^{\circ} \mathrm{C}$ for 24 hours. Experiments were performed with an insect density of $1,2.5,5,15$, and 30 insects per $\mathrm{kg}$ rice and at temperatures of 20,25 , and $30^{\circ} \mathrm{C}$. The number of insects trapped in each tube was recorded after $24 \mathrm{~h}$, and the experiment was repeated three times.

To evaluate the attractiveness of food mixture M17 on different species of storedgrain pests, a $50 \mathrm{~mL}$ type trap was used, with most flasks baited with $7.6 \mathrm{~g}$ food mixture M17 and one left empty as a control. Four species of stored-grain pests, Tribolium castaneum, Sitophilus oryzae, Cryptolestes ferrugineus, and Rhizopertha dominica were investigated, and 30 insects from one species were used in each experiment. The experiments were kept in an incubator at $30 \pm 1^{\circ} \mathrm{C}$ and $75 \% \mathrm{RH}$ in the dark.

\subsection{Determination of the time for which food mixture M17 remains effective}

In the lab, 140 insects were dispersed equally through rice in a plastic box $(24 \mathrm{~cm} \times$ $34 \mathrm{~cm} \times 18.5 \mathrm{~cm}$ ). Two $50 \mathrm{~mL}$ traps were inserted into rice $20 \mathrm{~cm}$ apart, and the traps were baited with either $7.6 \mathrm{~g}$ of food mixture M17 or nothing, as a control. The number of insects in each tube was recorded regularly after $1,3,7,14,25,35$, and 40 days. After each observation, the trapped insects were removed from the traps, and an equal number were added to the rice box; the positions of the two traps were also swapped each day. The experiment was conducted in darkness at $28 \pm 2{ }^{\circ} \mathrm{C}$ and $70 \% \mathrm{RH}$, and was repeated three times.

Further experiments were conducted in a granary in Zhejiang Yuezhou Industrial Co., Ltd., (Zhejiang, China) from June 21 to August 1 in 2019. The granary was $25.2 \mathrm{~m} \times$ $18 \mathrm{~m}$, and contained about $2000 \mathrm{~T}$ rice. For the granary experiments, $100 \mathrm{~mL}$ type tube traps (diameter $4 \mathrm{~cm}$, height $11 \mathrm{~cm}$ ) were used. In each experiment, three tubes were baited with $7.6 \mathrm{~g}$, $50 \mathrm{~g}$, or $100 \mathrm{~g}$ of food mixture M17 respectively, and a fourth was left empty as a control. The four tubes were inserted into the rice and arranged in a $40 \times 40 \mathrm{~cm}$ square, and the places of the four tubes were exchanged randomly after each insect count had taken place. 
The trapping rate and the time for which the commercial attractant Xlure MT (https://russellipm.com/) and food mixture M17 remained effective were determined using the methods described above with slight modifications. One Xlure MST and three Xlure MST trap sets (Figure S3, https://russellipm.com/) baited with $7.6 \mathrm{~g}$, or $22.5 \mathrm{~g}$ of M17 or left empty as a control were placed on the surface of the rice arranged in a $20 \times 20 \mathrm{~cm}$ square. Eighty adult insects were released in this experiment.

\subsection{Collection of food mixture volatiles and GC-MS analysis}

Volatiles released from the food mixture M17 were collected as previously described [40]. $3 \mathrm{~g}$ of food mixture M17 was placed in a $35 \mathrm{~mL}$ glass collecting bottle, and a vacuum pump was used to extract gas at $400 \mathrm{~mL} / \mathrm{min}$. An adsorption tube containing $40 \mathrm{mg}$ of absorbent PoraPak ${ }^{\mathrm{TM}} \mathrm{Q}$ (80-100 mesh) was connected between the bottle and the vacuum pump to absorb the volatile matter from food mixtures M17 (Figure S4). After $8 \mathrm{~h}$ of adsorption, each adsorption tube was eluted with $200 \mu \mathrm{L}$ dichloromethane, and subsequently stored at $-40^{\circ} \mathrm{C}$.

Chemical analysis was conducted using a GCMS-QP2010 Plus equipped with an HP5 capillary column $(30 \mathrm{~m} \times 0.25 \mathrm{~mm}$ id, $0.25 \mu \mathrm{m}$ film $)$. The carrier gas was helium, with a flow rate of $1 \mathrm{~mL} / \mathrm{min}$. Samples $(2 \mu \mathrm{L})$ were injected into the column with a split ratio of 1:1. The component separation temperature was programmed to rise from $100^{\circ} \mathrm{C}$ to $250^{\circ} \mathrm{C}$ at a rate of $8^{\circ} \mathrm{C} / \mathrm{min}$ and was then held at $250^{\circ} \mathrm{C}$ for $10 \mathrm{~min} 25 \mathrm{~s}$. The percentage composition was calculated by integrating the GC peak area normalization. The identification and quantification of compounds in the food mixture volatiles has been described in [41] based on standard samples and mass spectrum Library NIST11.LIB analysis. The retention index under temperature programmed conditions was calculated for each selected compound [42].

\subsection{The attractiveness of food volatiles and chemicals as estimated using an olfactometer.}

Six-armed or four-armed olfactometer assays (Figure S5) were carried out as previously described [41] with little modification. The air flow in each arm of the olfactometer was $200 \mathrm{~mL} / \mathrm{min}$, and in each experiment, 90 insects (six-armed olfactometer) or 60 insects (four-armed olfactometer) were released. After $25 \mathrm{~min}$, the number of insects that had moved down an olfactometer arm at least $5 \mathrm{~cm}$ were recorded. Each assays was repeated four times. For volatile eluents and chemicals, $20 \mu \mathrm{L}$ solution at different concentrations was applied to a natural rubber septa (for diameter $1 \mathrm{~cm}$ tubes), and the solvent was allowed to evaporate into the air for $1 \mathrm{~min}$ before the olfactometer experiment took place.

\subsection{GC-EAD and EAG Assays}

To determine whether the chemicals from food volatiles were able to stimulate O. surinamensis antennae, a GC-EAD analysis was conducted. Nitrogen with a flow rate of $1 \mathrm{~mL} / \mathrm{min}$ was used as a carrier gas [41]. Samples $(1 \mu \mathrm{L})$ were injected (splitless mode) into the column and the oven temperature was programmed to hold initially at $100{ }^{\circ} \mathrm{C}$ for 1 min, and was then ramped to $250{ }^{\circ} \mathrm{C}$ at $8^{\circ} \mathrm{C} / \mathrm{min}$, with a final hold for $10 \mathrm{~min} 25 \mathrm{~s}$ at 250 ${ }^{\circ} \mathrm{C}$. The active components were identified by retention index and GC-MS technology. At least five $O$. surinamensis antennae were measured for each treatment.

For EAG recordings, an adult $O$. surinamensis head with antennae was excised from its body using a scalpel. The tips of the antennae were cut slightly and inserted into one glass capillary, and another glass capillary was connected to the severed head neck to form a closed electrical circuit [41]. Different concentrations of volatiles or chemicals were prepared in dichloromethane, and in each experiment, $10 \mu \mathrm{L}$ of one preparation was added to a piece of folded filter paper $(3 \mathrm{~cm} \times 1 \mathrm{~cm})$, and allowed to evaporate for one minute before being placed into a glass Pasteur pipette as the stimulus for the EAG recordings. Dichloromethane alone was used as a control at the start and end of each recording. Average antenna EAG values of tested volatiles or chemical (Ev), solvent di- 
chloromethane $\left(\mathrm{E}_{\mathrm{c}}\right)$ and $1000 \mathrm{mg} / \mathrm{L}$ benzaldehyde $(\mathrm{Es})$ were recorded, and the EAG responsive index EA of antennae to volatiles or chemicals was calculated according to the formula: $E_{A}=\left(E_{V}-\odot E_{c}\right) /\left(E_{s}-\odot E_{c}\right)[43]$. For each EAG assay, at least six replicates of treatment were carried out.

\subsection{Data analysis}

The experimental data were analyzed using the DPS@ Data Processing System 18.1 [44] (http://www.dpsw.cn/). The relative attractiveness of single foods, the attractiveness of food mixtures, the effect of the food mixtures under different temperatures and insect densities, and the EAG response data were analyzed using a one-way ANOVA. A total of 18 food combinations were designed using orthogonal experimental design. For the olfactometer data, we used generalized linear mixed models (GLMMs) with Poisson distribution of error, and the replicates were treated as the random factor. The data of trapping rate of the individual foods and the food volatiles were statistically analyzed after an arcsine transformation.

\section{Results}

\subsection{Relative attractiveness of foods to O. surinamensis and efficiency of attraction of food mix-} tures

Thirty-eight foods showed different relative attractiveness, ranging from 0.02 to 13.70 based on the attractiveness of flour to ORSU (Figure 1). The seven foods with higher relative attractiveness from 13.70 to 4.32 were oatmeal, dried fig, sucrose, hawthorn, cashew, millet, and wolfberry in order (Figure 1). Because the soft dried wolfberry fruits go bad easily, wolfberry was not selected as a component of any of the food mixtures (Table1). The six foods with the highest relative attractiveness were combined into a "cocktail" food attractant, and 18 food mixtures were designed using an orthogonal design (Table1). The trap bioassay results suggested that the food mixtures M17, M16 and M2 have the highest trapping rates, 10.55, 6.63, and 6.62\%, respectively (Figure 2A). Bioassay data suggested that the six food mixtures, including M17, were able to trap ORSU effectively, and food mixture M17 had the highest attractiveness, about 1.24 - 1.66 times that of the other five food mixtures and significantly higher than the attractive activity of either M6 or the blank control treatment (Figure 2B). Compared to the commercial attractant trap Xlure MST, the trapping rate of food mixture M17 was about 2.66 - 10.72 times as high (Figure 2C). The trapping rate of traps baited with $1 \mathrm{~g}$ food mixture M17 were all significantly higher than those baited with Xlure MST or the control treatments over the total 21-day duration of the experiments, and at the 21st day, the trapping rate of traps baited with M17 was $66.70 \%$, which was 5.63 and 33.86 times higher than those of Xlure MST and the control, respectively (Figure 2C). Food mixtures M17 was therefore used for further analysis. 


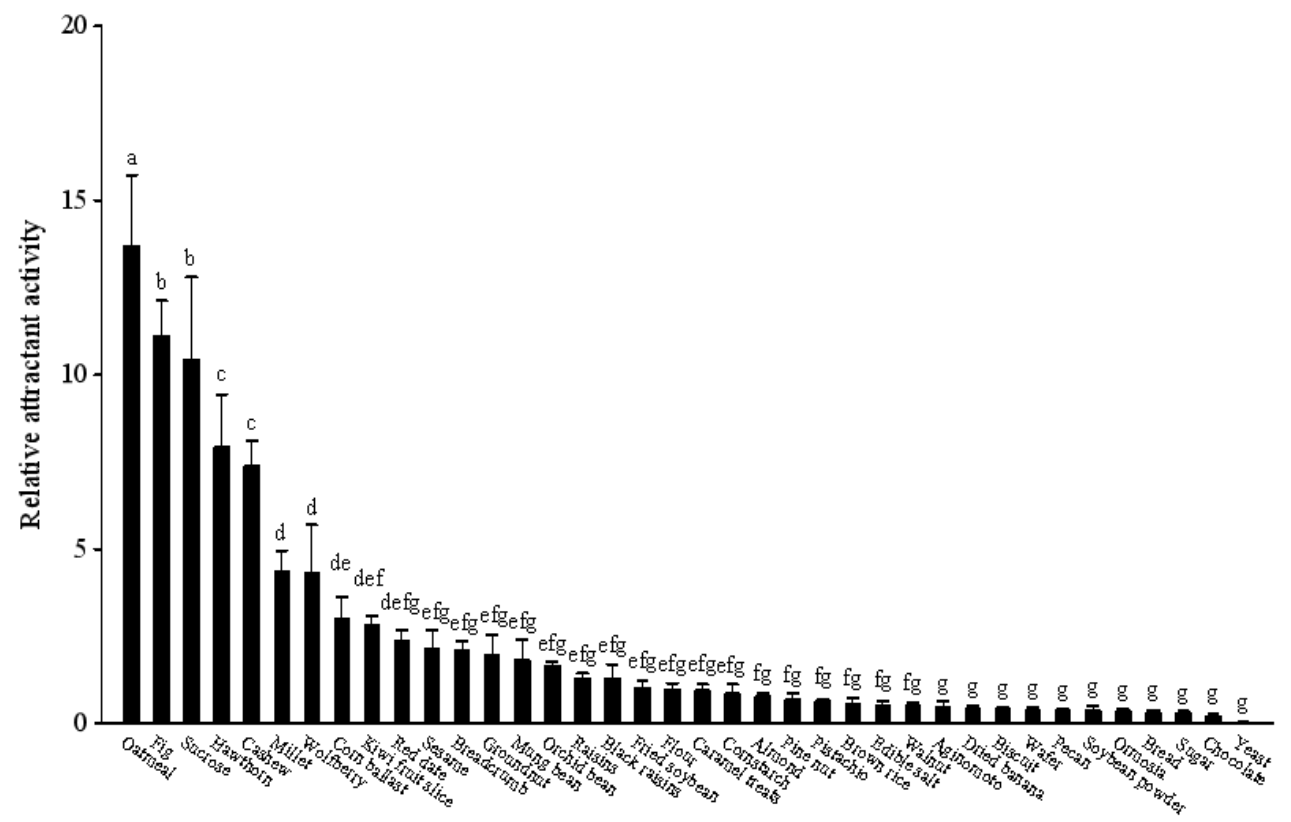

Figure 1. Relative attractiveness of thirty-eight kinds of food to ORSU adults. The letters represent significant differences among treatments $(P<0.05)$

Table1. Eighteen food mixtures composed of six individual foods, based on an orthogonal design

\begin{tabular}{|c|c|c|c|c|c|c|}
\hline $\begin{array}{c}\text { Mixture } \\
\text { No. }\end{array}$ & Oatmeal & $\begin{array}{c}\text { Haw- } \\
\text { thorn }\end{array}$ & Millet & Sucrose & $\begin{array}{c}\text { Cashew } \\
\text { nuts }\end{array}$ & Fig \\
\hline M1 & A1 & B2 & C2 & D1 & E2 & F3 \\
\hline M2 & A2 & B1 & C3 & D2 & E2 & F1 \\
\hline M3 & A3 & B1 & C2 & D2 & E3 & F3 \\
\hline M4 & A1 & B3 & C1 & D2 & E2 & F3 \\
\hline M5 & A2 & B1 & C1 & D3 & E1 & F3 \\
\hline M6 & A3 & B3 & C2 & D1 & E1 & F1 \\
\hline M7 & A3 & B1 & C3 & D1 & E2 & F2 \\
\hline M8 & A2 & B2 & C2 & D3 & E2 & F1 \\
\hline M9 & A2 & B3 & C2 & D2 & E1 & F2 \\
\hline M10 & A3 & B3 & C1 & D3 & E2 & F2 \\
\hline M11 & A1 & B1 & C1 & D1 & E1 & F1 \\
\hline M12 & A2 & B2 & C1 & D1 & E3 & F2 \\
\hline M13 & A2 & B3 & C3 & D1 & E3 & F3 \\
\hline M14 & A3 & B2 & C1 & D2 & E3 & F1 \\
\hline M15 & A3 & B2 & C3 & D3 & E1 & F3 \\
\hline M16 & A1 & B2 & C3 & D2 & E1 & F2 \\
\hline M17 & A1 & B3 & C3 & D3 & E3 & F1 \\
\hline M18 & A1 & B1 & C2 & D3 & E3 & F2 \\
\hline
\end{tabular}

Notes: The letters A1, A2 and A3 represent the different weights of oatmeal, $0.25 \mathrm{~g}, 0.5 \mathrm{~g}$ and $1 \mathrm{~g}$, respectively; B1, B2 and B3 represent the different weights of hawthorn, $0.35 \mathrm{~g}, 0.7 \mathrm{~g}$ and $1.4 \mathrm{~g}$, respectively; C1, C2 and C3 represent different weights of millet, $0.45 \mathrm{~g}, 0.9 \mathrm{~g}$ and $1.8 \mathrm{~g}$, respectively; D1, D2 and D3 represent different weights of sucrose, $0.6 \mathrm{~g}, 1.2 \mathrm{~g}$ and $2.4 \mathrm{~g}$, respectively; E1, E2 and 
E3 represent different weights of cashew nuts, $0.35 \mathrm{~g}, 0.7 \mathrm{~g}$ and $1.4 \mathrm{~g}$, respectively; and F1, F2 and F3 represent different weights of figs, $0.35 \mathrm{~g}, 0.7 \mathrm{~g}$ and $1.4 \mathrm{~g}$, respectively.
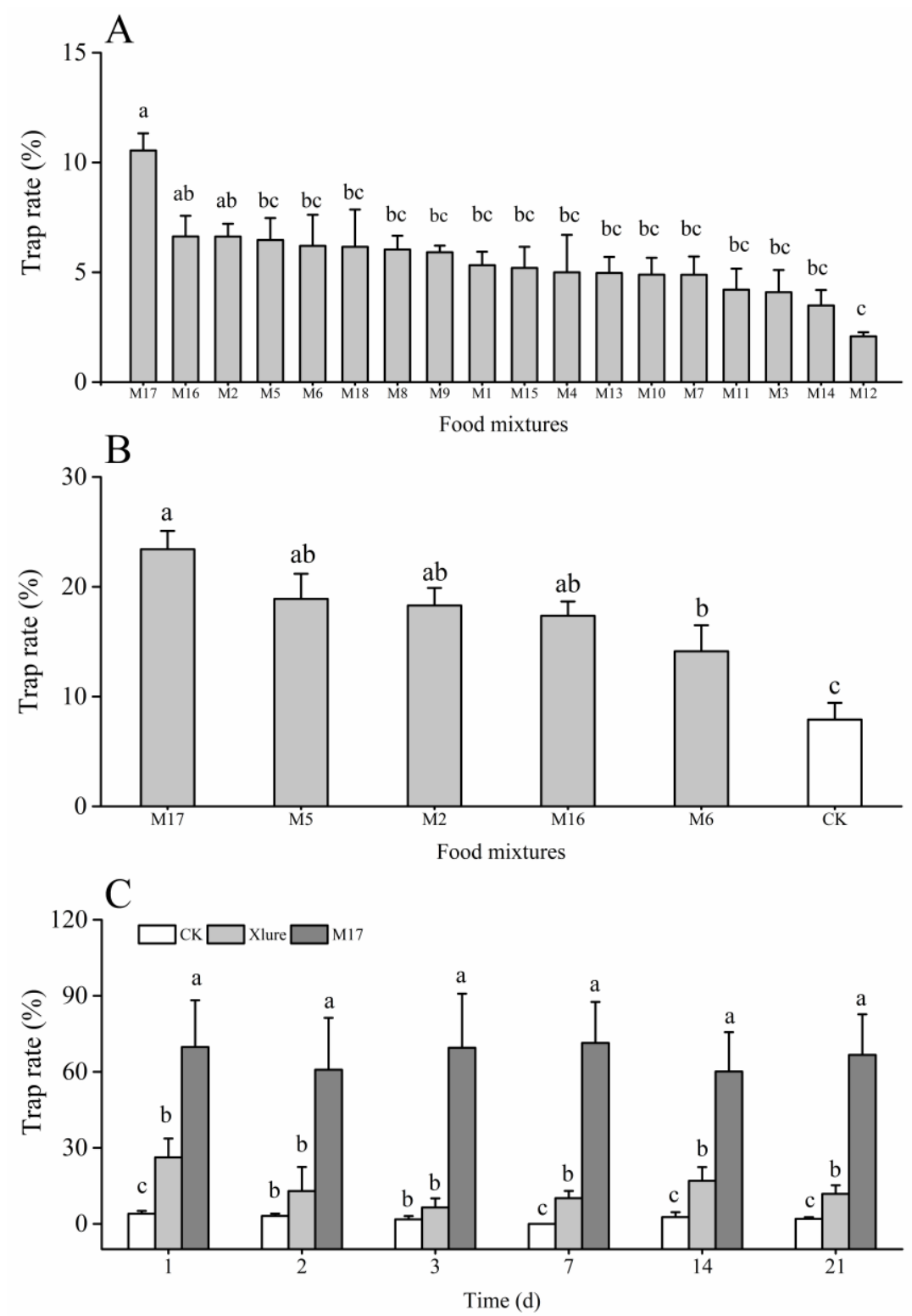

Figure 2. The efficiency of attraction of food mixtures to ORSU adults. (A) Efficiency of attraction of 18 food mixtures. (B) Efficiency of attraction of 6 food mixtures. (C) Comparison with commercial food attractant XLure and food mixture M17 $(1 \mathrm{~g})$ in lab. CK, control treatment. The letters represent significant differences among treatments $(P<0.05)$. 
Both insect population density and environmental temperature were able to influence how many ORSU were trapped by traps baited with food mixture M17. At an insect population density of one insect per $\mathrm{kg}$ grain, $19.05 \%$ of ORSU could be trapped in 24 hours. At a population density of 2.5 ORSU per kg grain, traps baited with M17 reached a maximum trapping effectiveness of $58.10 \%$, but with further increases in insect population density, the trapping rate of traps baited with M17 decreased to minimum of $17.70 \%$ at 30 insects per $\mathrm{kg}$ grain (Figure 3A). Trapping rate of M17 traps were higher given insect population densities of 2.5-15 insects per $\mathrm{kg}$ grain at 1 and 30 insects per kg grain (Figure $3 \mathrm{~A})$. It is interesting that all three studied temperatures, there were significant differences between attractiveness of M17 and the control group, and the trapping rates of M17 traps were $12.31,4.88$, and 9.76 times those of the blank control treatments at the same temperature. The highest trapping rate observed for the M17 traps was $65.00 \%$ at temperature 25 ${ }^{\circ} \mathrm{C}$, which was obviously higher than the $18.99 \%$ and $19.44 \%$ observed at temperatures of $20^{\circ} \mathrm{C}$ and $30^{\circ} \mathrm{C}$, respectively.
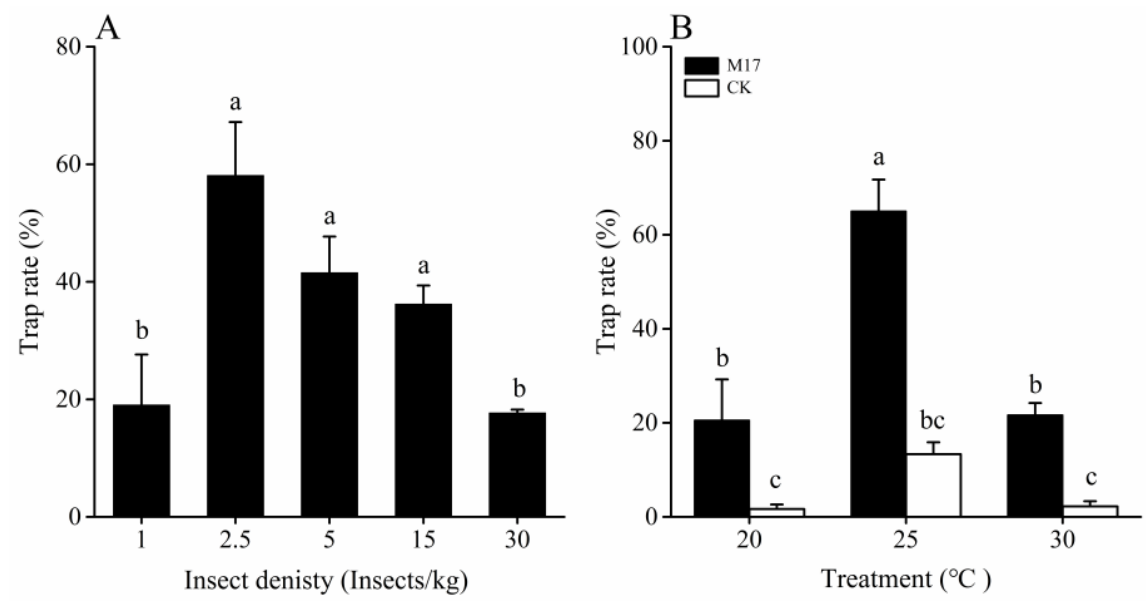

Figure 3. The efficiency of attraction of food mixtures to ORSU adults. (A) Efficiency of attraction of 18 food mixtures. (B) Efficiency of attraction of 6 food mixtures. (C) Comparison with commercial food attractant XLure and food mixture M17 $(1 \mathrm{~g})$ in lab. CK, control treatment. The letters represent significant differences among treatments $(P<0.05)$.

\subsection{Time over which food mixture M17 remained attractive}

In the lab, with an insect density of 10 insects per $\mathrm{kg}$ grain, food mixture M17 remained attractive for a significant time. After 40 days, the trapping rates of M17 traps over $24 \mathrm{~h}$ were $69.44 \%-88.15 \%$, and all were significantly higher than those of the control treatments (Figure 4A). On the first day of trapping, the M17 baited tubes were able to trap $88.15 \%$ of the ORSU, with the average $24 \mathrm{~h}$ trapping rate slowing to $69.44 \%$ after seven days, then maintaining a rate of between $86.99 \%$ and $77.38 \%$ to forty days. After forty days, the attractant M17 under laboratory conditions was still effective, with a trapping rate of $77.38 \%$, which was significantly higher than the control (Figure 4A). Moreover, both $7.6 \mathrm{~g}$ and $22.8 \mathrm{~g}$ of M17 could attract significantly more insects at all time points after seven days and 38-47 days compared to both the the positive control (the commercial attractant Xlure) and the blank control (Figure 4B). It is interesting that no differences were found between the trapping rates of traps baited with $7.6 \mathrm{~g}$ and $22.8 \mathrm{~g} \mathrm{M} 17$ at any time points (Figure 4B) in the lab. In addition, both the attractiveness and the time over which food mixture M17 remained attractive were measured in a granary containing $2000 \mathrm{~T}$ rice. Measured over a 1 - 40 day period showed significant differences in the trapping rate between the blank controls and the treatment traps $\left(\mathrm{F}_{3,54}=3.5790, \mathrm{P}=0.0196\right)$ were visible each day (Figure 4C). In the first three days, the traps baited with $100 \mathrm{~g} \mathrm{M17}$ always had the highest trapping rate, which was significantly higher than that of the blank treatment. At seven days, all three M17 treatments obviously trapped more ORSU than did the blank treatment, and at 40 days, the average trapping rate of traps baited with $7.6 \mathrm{~g} \mathrm{M} 17$, were 
$50.67 \%$, higher than any other treatment and apparently also higher than that of the positive control (Figure 4C).
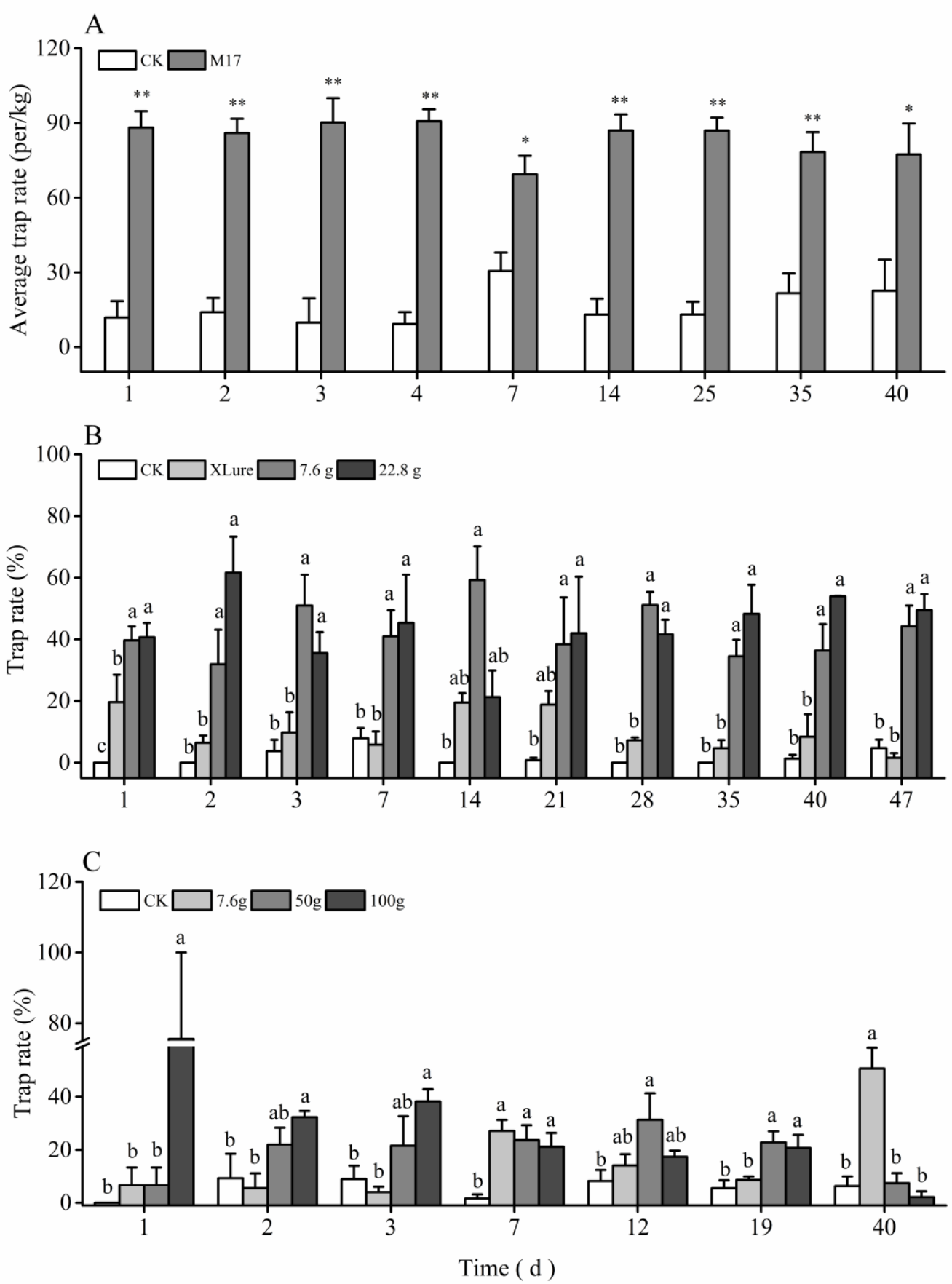

Figure 4. The duration of attractiveness of the food mixture M17 in the lab and in the largescale granary. (A) The duration of attractiveness of food mixture M17 in the lab. (B) The attractiveness of the commercial food attractant XLure and food mixture M17 in the lab over 47 days. (C) Attractiveness of food mixture M17 in the large-scale granary over 40 days. CK, control. The letters represent significant differences between treatments at the same time points $(P<0.05)$ and stars indicate significant differences between treatment and control as tested with t-tests $\left({ }^{*}, P<0.05 ;{ }^{* *}\right.$, $P<0.01)$.

\subsection{Food mixture M17 was able to effectively attract other stored grain pests}


Food mixture M17 was obviously attractive not only to ORSU, but also to four other stored-grain pests (T. castaneum, C. ferrugineus, S. oryzae and R. dominica), with trapping rates of $41.11 \%, 46.67 \%, 68.89 \%$, and $8.89 \%$, respectively, which are about $12.35,14.01$, 4.13 and 8.01 times those of the control treatment (Figure 5A). The volatiles from M17 were collected and the antenna EAG responses to these volatiles were then assessed. Consistent with the M17 trapping rates of the four pests (Figure 5A), the responses of the antennae from all four pests to M17 volatiles were markedly higher than to the control treatment, with the EAG values ranging from 0.09 to $1.17 \mathrm{mV}$ (Figure 5B). However, in comparison to the control, the M17 volatiles were only successful in trapping more C. ferrugineus or S. oryzae (Figure 5C).
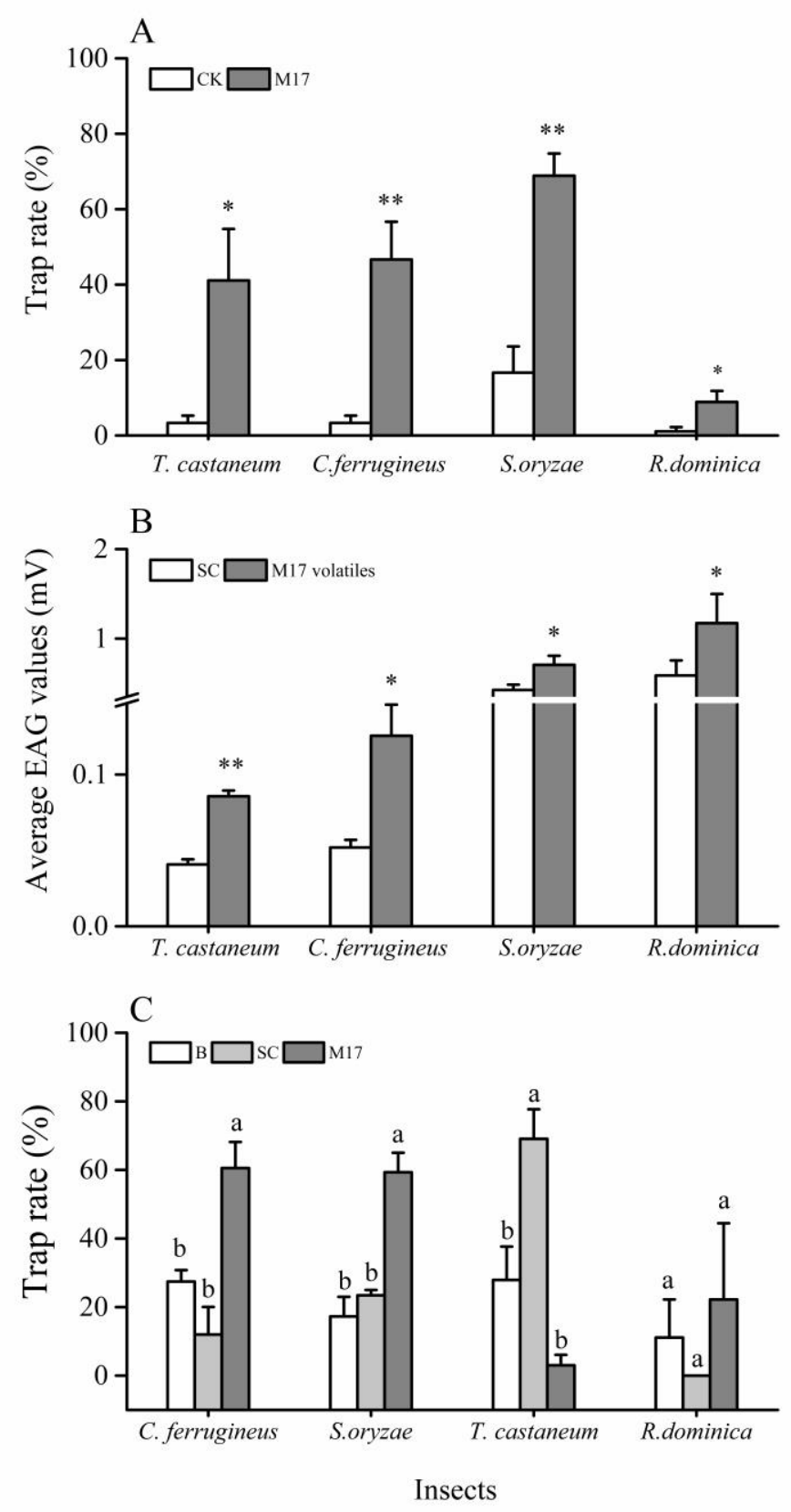

Figure 5. Effect of food mixture M17 on different stored grain pests.(A) Attractiveness of food mixture M17 to the stored-grain pests T. castaneum, C. ferrugineus, S. oryzae, R. dominica. (B) Antenna EAG responses of different stored-grain pests to eluent of the volatiles from food mixture M17. (C) Behavioral responses of different stored grain pests to eluent of the volatiles from food mixture M17. B, blank treatment control; SC, control treatment with $10 \mu \mathrm{L}$ dichloromethane; M17, food mixture M17. Stars represent significant differences between the treatments at the same time as tested with 
t-tests $\left({ }^{*}, P<0.05 ;{ }^{* *}, P<0.01\right)$; The letters represent significant differences between treatments at the same time points $(P<0.05)$.

\subsection{The volatiles from food mixture M17 were obviously attractive to ORSU}

In order to find out whether the volatiles from food mixture M17 played an important role in its attractiveness to $O$. surinamensis, we performed a series of six-arm and four-arm olfactometer assays. The results show that ORSU preference for M17 volatiles was significantly $(27.24 \%)$ higher than for any of the other five treatments, including the flour treatment and the blank control (Figure 6A). Nevertheless, no preference was found between volatiles from sucrose, cashew, fig, millet, or oatmeal singly, five of the six components of M17, compared to the blank control (Figure 6B and 6C). The volatiles from the sixth component of M17, hawthorn, were, however, significantly more attractive to ORSU than the other treatments and the blank control $(36.67 \%),(C)$, which suggests that hawthorn volatiles may play a major role in the attraction of ORSU to the food mixtures. We then compared the attractiveness of volatiles released by the hawthorn slices with those from food mixtures M17, and found that the number of ORSU preferring food mixture M17 was about 4.73 times that preferring hawthorn alone (Figure 6D).
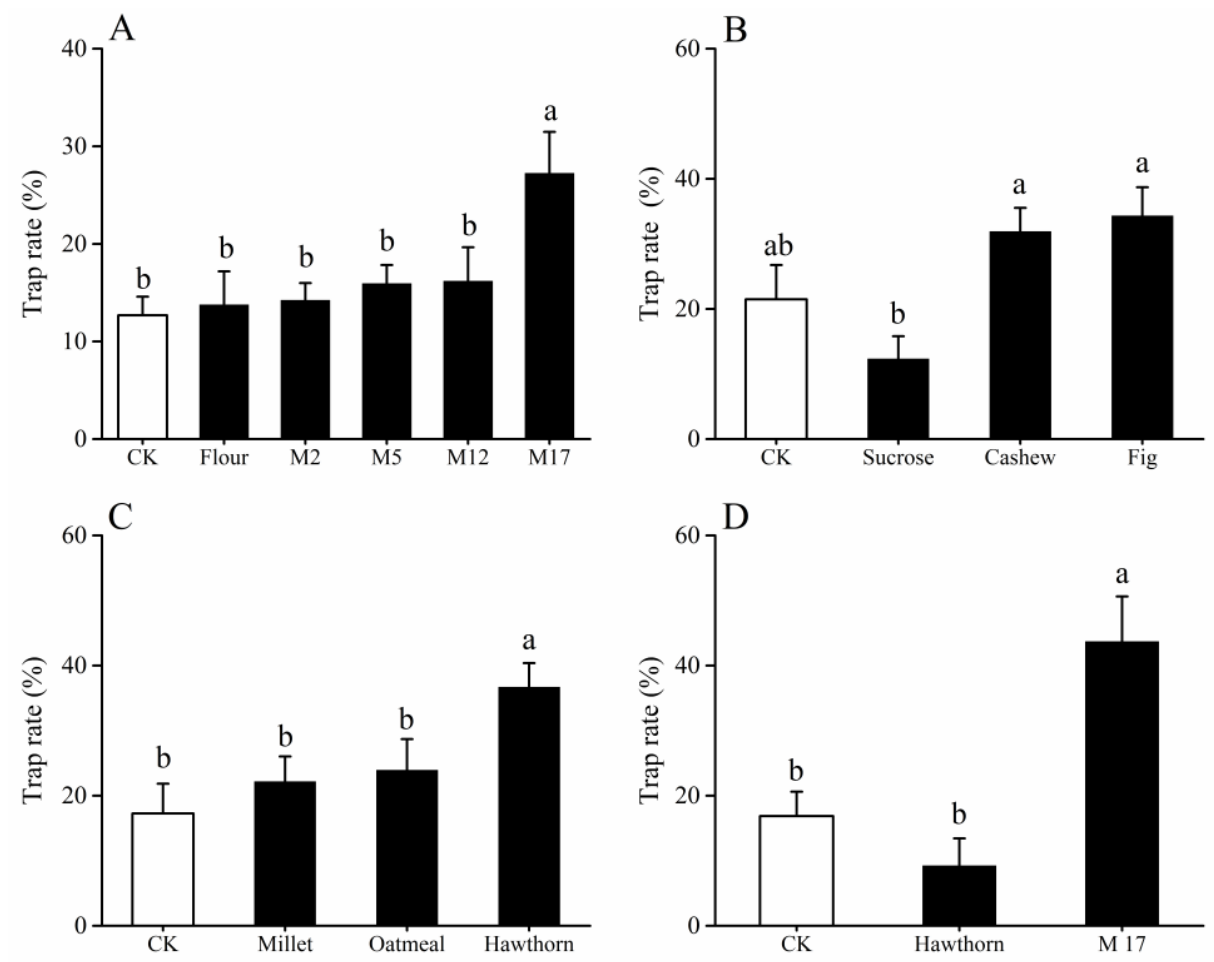

Treatments

Figure 6. Reactions of ORSU to volatiles released by food mixtures or single foods. (A) ORSU preferences regarding volatiles released from mixtures of different foods. (B) and (C) ORSU preferences regarding volatiles released from individual foods. (D) Reaction of ORSU to food mixture M17 and hawthorn volatiles. CK, control treatment; M2, M5, M12, M17, represent food mixtures. The letters represent significant differences among treatments $(\mathrm{P}<0.05)$.

The volatiles released by food mixture M17 were collected by headspace dynamic adsorption and eluted with dichloromethane. We ran an experiment comparing ORSU attraction to the eluent from the M17 volatiles to dichloromethane and to a blank control. The results indicated that compared with the blank, and dichloromethane, eluent from the volatiles from food mixture M17 was significantly more attractive to ORSU, with trapping rates of $40.08 \%$ with (Figure $7 \mathrm{~A}$ ) and $31.25 \%$ without (Figure $7 \mathrm{~B}$ ) airflow in the tubes 
of a four-arm olfactometer. There were no significant differences between the electrophysiological responses of ORSU antennae to volatiles collected from $3 \mathrm{~g}$ or $300 \mathrm{~g}$ M17, however, the antenna EAG values of volatiles eluent from $3 \mathrm{~g}$ and $300 \mathrm{~g}$ food mixture M17 was 1.96 and 2.24 times as high as the EAG values from the solvent control, respectively, both with significant differences (Figure 7C). The antenna EAG value of the response to M17 volatiles eluent was $0.157 \mathrm{mV}$, which was apparently higher than the $0.032 \mathrm{mV}$ response of the antennae to the solvent control (Figure 7D), however there were no differences between the antenna electrophysiological responses to volatiles eluent when the eluent was diluted 10-10 000 times (Figure 7D).
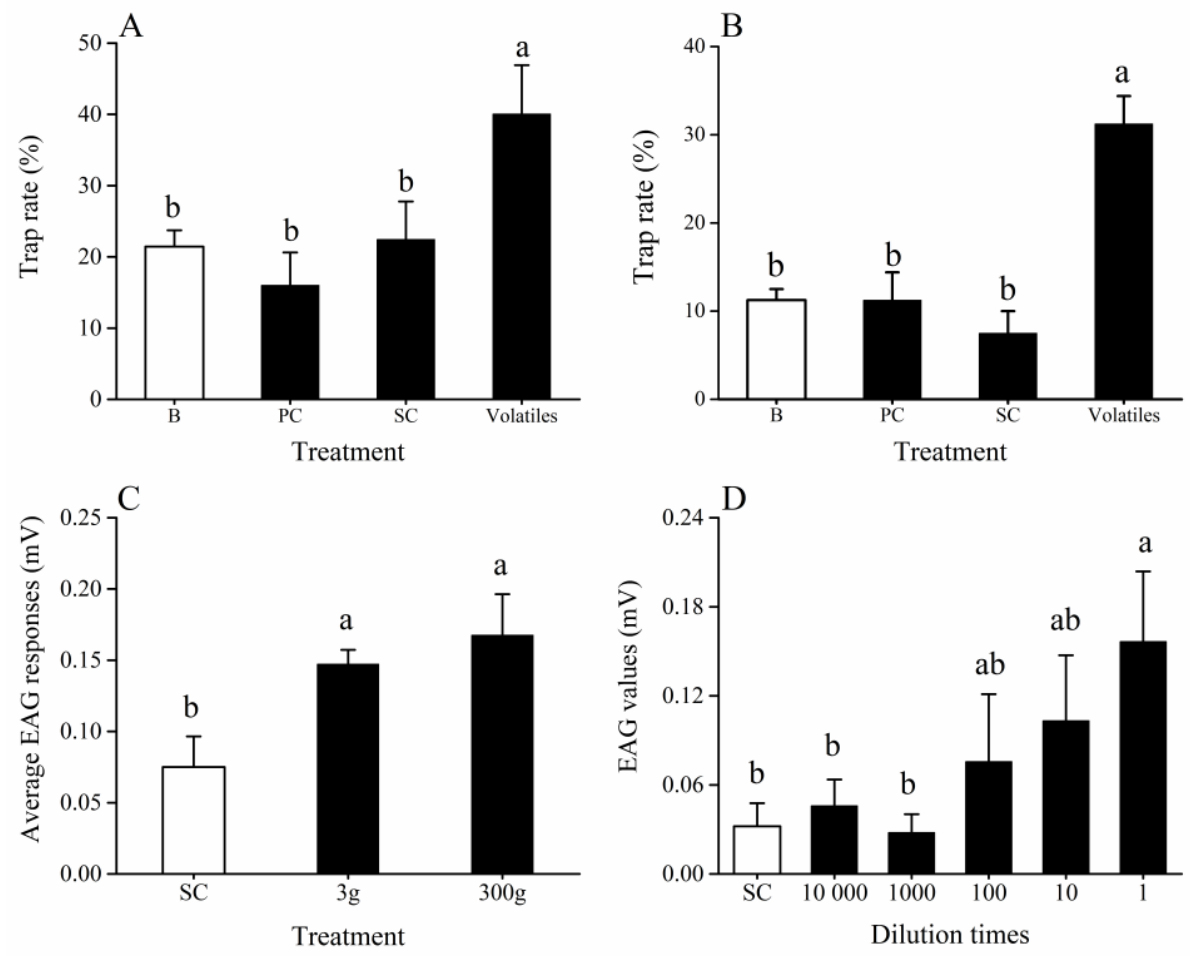

Figure 7. The attractiveness of an eluent of the volatiles from food mixture 17 to ORSU and the electrophysiological activity stimulated by this eluent. The attractiveness of and eluent of volatiles from M17 to ORSU adults with (A) or without (B) airflow. (C) Average ORSU antenna EAG responses to the eluent of volatiles from $3 \mathrm{~g}$ and $300 \mathrm{~g}$ of M17 food mixture. (D) Average antenna EAG responses of ORSU to different concentrations of an eluent of volatiles extracted from M17. The letter ' $\mathrm{B}$ ' on the $\mathrm{x}$-axis indicates the blank control; PC, natural rubber septa; SC, natural rubber septa with solvent dichloromethane. The small letters over the bars represent significant differences among treatments $(P<0.05)$.

\subsection{The bioactive compounds in food mixture M17 volatile eluent}

GC-EAD analysis indicated that eight compounds in the volatiles eluent from the food mixture had obvious antenna electrophysiological activity (Figure 8). We were able to identify six of these compounds using GC-MS and comparisons with chemical standards and retention index confirmation. The chemicals were identified as nonanal (peak 2, with a retention time (RT) of $5.32 \mathrm{~min}$ ); dodecane (peak 3, RT $6.51 \mathrm{~min}$ ); tridecane (peak 4, RT 8.07 min); $\beta$-caryophyllene (peak 5, RT 10.23 min); methyl palmitate (peak 6, RT 16.98 min), and dibutyl phthalate (peak 7, RT $17.52 \mathrm{~min}$ ) (Figure 8 and Table 2). 


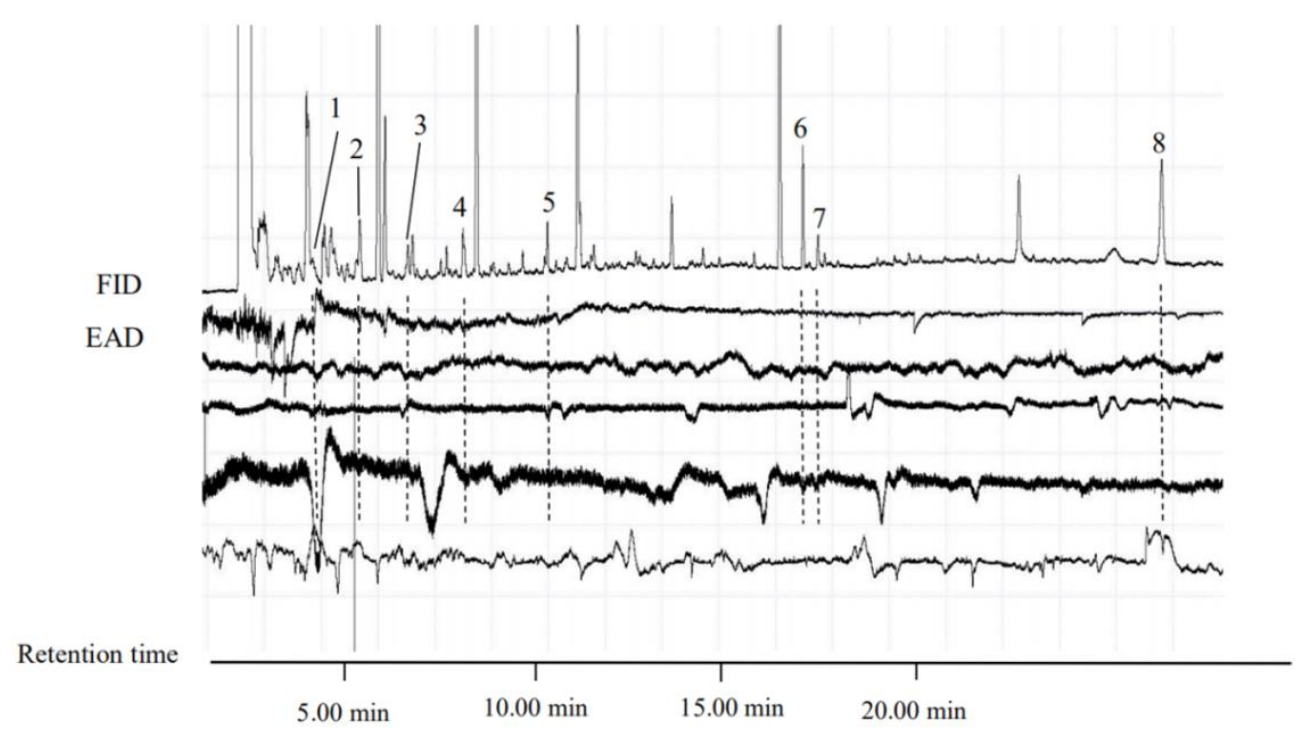

Figure 8. GC-EAD analysis of $\mathrm{O}$. surinamensis antennae responses to eluent of M17 volatiles.Upper trace, gaschromatogram of GC; Lower four trace, EAG response of different antennae. Peak $1=$ unknown, $2=$ nonanal, $3=$ dodecane, $4=$ tridecane, $5=\beta$-caryphyllene, $6=$ methyl palmitate, 7 = dibutyl phthalate, $8=$ unknown.

Table2. Chemicals in food mixture M17 volatiles that resulted in ORSU antenna electrophysiological activity.

\begin{tabular}{|c|c|c|c|c|c|c|c|}
\hline No. & $\begin{array}{l}\text { Retention } \\
\text { time }\end{array}$ & Compound & $\mathrm{RI}^{\mathrm{a}}$ & $\mathrm{RI}^{\mathrm{b}}$ & Amount (\%) ${ }^{c}$ & CAS No. & Structural formula \\
\hline 1 & 4.39 & Unknown & - & 1002 & $0.005 \%$ & - & - \\
\hline 2 & 5.32 & Nonanal & 1104 & 1104 & $0.53 \%$ & $124-19-6$ & \\
\hline 3 & 6.51 & Dodicane & 1214 & 1200 & $0.17 \%$ & $112-40-3$ & W \\
\hline 4 & 8.07 & Tridecane & 1313 & 1300 & $0.1 \%$ & $629-50-5$ & MW \\
\hline 5 & 10.23 & $\beta$-Caryophyllene & $1425^{\mathrm{d}}$ & 1436 & $0.22 \%$ & $87-44-5$ & \\
\hline 6 & 16.98 & methyl palmitate & 1878 & 1826 & $12.3 \%$ & $112-39-0$ & \\
\hline 7 & 17.52 & Dibutyl phthalate & 2037 & 1966 & $0.14 \%$ & $84-74-2$ & \\
\hline 8 & 26.66 & Unknown & - & - & $0.22 \%$ & - & - \\
\hline
\end{tabular}

a Retention index (RI) retrieved from the NIST08 mass spectrometry database; b Retention index calculated in relation to the series of n-alkanes (C7-C40) in lab; c Relative percentage of the identified volatiles based on GC-FID; d Retention index obtained from the literature [40].

The EAG responses of ORSU antenna to these six chemicals were measured, and compared to the control, nonanal (10-10000 ppm), $\beta$-caryophyllene (1000 ppm and 100000 ppm), dodecane (10000 ppm) and dibutyl phthalate (10 ppm) treatments could cause significantly higher EAG responses (Figure 9A). The trapping rate of the six compounds individually was assessed using concentrations of 100 times that of the original volatiles eluent. Our results showed that nonanal, dodecane tridecane, $\beta$-caryophyllene, and dibutyl phthalate could individually trap significantly more insects than the control treatment, with trapping rates of 5.42, 5.72, 7.58, 4.84, 2.62 times that of that of control, respectively (Figure 9B). However, a mixture of nonanal and $\beta$-caryophyllene (both 100 times of the concentration in the original volatile eluent) did not show obvious attractiveness, and neither did adding the other chemicals one by one to the mixture (Figure 9C). It is interesting that a mixture of the five chemicals nonanal, $\beta$-caryophyllene, dodecane, tridecane, and dibutyl phthalate at the concentrations of the original volatile eluent were slightly more 
attractive to ORSU than the control, but the attractiveness increased to a maximum of $18.18 \%$ when methyl palmitate was added to the mixture (Figure 9D).
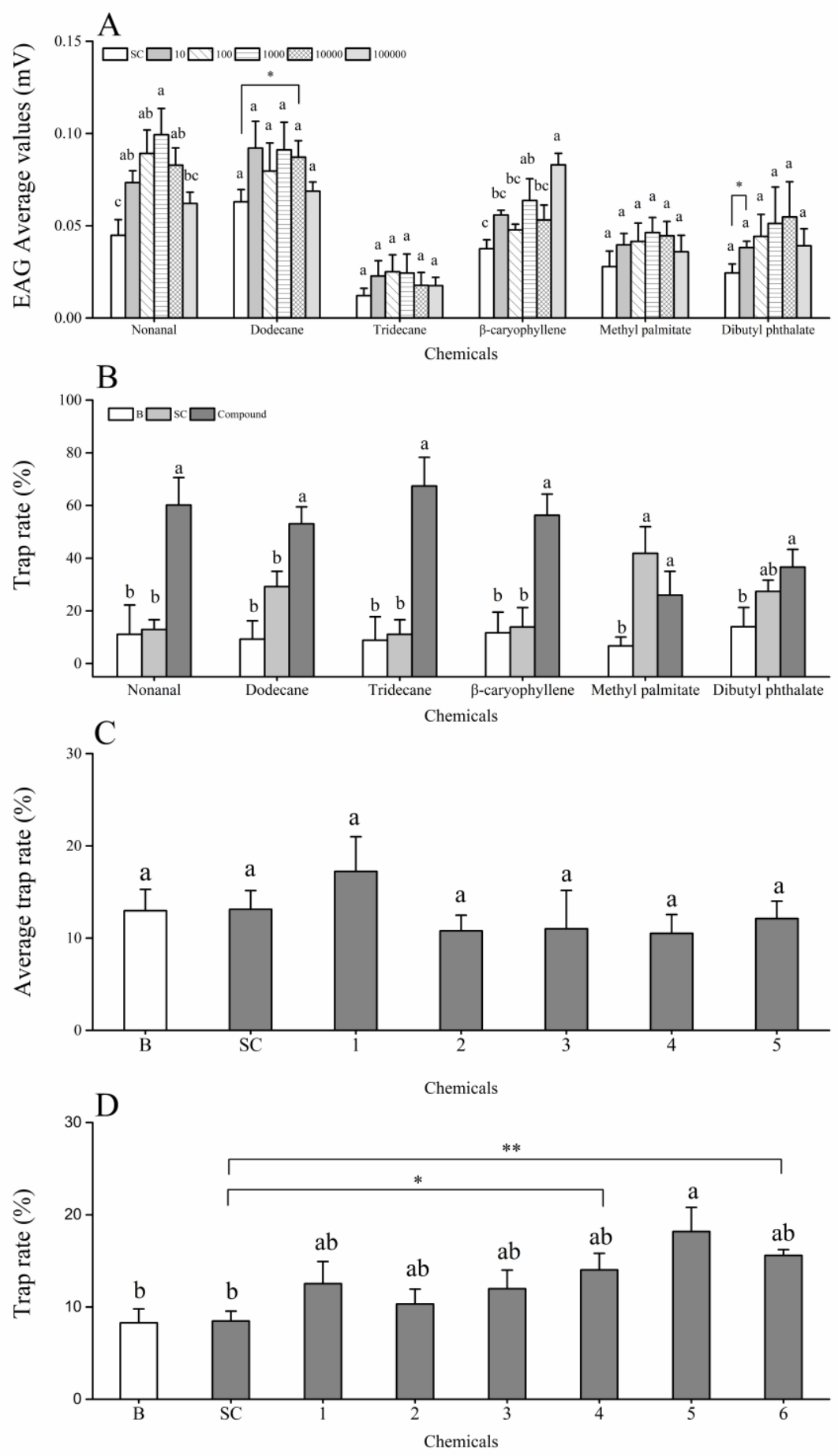

Figure 9. Electrophysiological and bioassay responses of ORSU antennae to different chemicals. (A) Average EAG responses of ORSU antennae to chemicals at different concentrations (ppm). (B) Selective bioassay of ORSU attraction to chemicals (100 ×original concentration in volatiles eluent). (C) Selective bioassay of ORSU attraction to mixtures of chemical, with each compound at concentrations of $100 \times$ that in the original volatiles eluent concentration. (D) Selective bioassay of ORSU attraction to mixtures of chemicals, with each compound at concentrations of $1 \times$ that in the original volatiles eluent. $\mathrm{B}$, blank control; $\mathrm{SC}$, solvent control dichloromethane; 1 , nonanal $+\beta$-caryophyllene; 2 , nonanal $+\beta$-caryophyllene+dodecane; 3 , nonanal $+\beta$-caryophyllene+dodecane+tridecane; 4 , nonanal $+\beta$-caryophyllene+dodecane+tridecane+dibutyl phthalate; 5 , nonanal $+\beta$-caryophyllene + dodec- 
ane+tridecane+dibutyl phthalate+methyl palmitate; 6, food mixture M17 volatiles. The letters represent significant differences among treatments $(P<0.05)$. Stars represents significant differences between treatment group and control $\left({ }^{*}, P<0.05 ;{ }^{* *}, P<0.01\right)$.

\section{Discussion}

Food based lures or attractants have been successfully used to control a variety of different pests, including tephritid fruit flies [45], Drosophila suzukii [46], Mediterranean fruit fly [47], cockroach $[45,48]$ and others. A great deal of work on the food selection behaviors of stored-product pests and attractants has also been carried out. The attractiveness of 30 different plant-based foods, most of which are used as condiments, including paprika (Capsicum annuum L., Solanaceae), cinnamon (Cinnamomum spp., Lauraceae), and turmeric (Curcuma longa L., Zingiberaceae) as potential food attractants for Lasioderma serricorne (F.) has been tested, and it was discovered that mulberry leaf tea was the strongest attractant of the tested materials [49]. In our assay, of 38 kinds of food, six foods (oatmeal, dried figs, sucrose, dried hawthorn, cashews, and millet) were particularly attractive to adult $O$. surinamensis, and we found that oatmeal was the most attractive to these beetles (Figure 1). Oatmeal was also reported to be the grain most attractive to adults of the the stored-grain pest Cryptolestes turcicus (Grouvelle), with selection rates as high as $41.1 \%$ in a bioassay experiment [50]. Our results also showed that hawthorn played an important role, but also that the trapping activity of food mixture M17 cannot be attributed solely to hawthorn (Figure 6C and D). In a laboratory, flight tunnel studies have confirmed that chocolate products and volatiles isolated from chocolate were attractive to Ephestia.cautella and Plodia interpunctella [51]. However, we found that chocolate was not particularly attractive to ORSU (Figure 1). This all suggests that the attractiveness of a certain food is very different to different insect species, and also that traps baited with food mixtures may be able to trap more insects than those with single foods alone. Furthermore, the proportions of different foods in food mixtures are critical. In our experiments involving 18 food mixtures, M17 was the mixture with the highest and steadiest attractiveness to ORSU (Figure 2).

Stored-product pests are primarily thermophilic in nature, and their growth and survival is greatly influenced by temperature [52]. Our data suggest that temperature is able to influence the attractiveness of food attractants. Food mixture M17 worked well at all three temperatures $\left(20,25\right.$, and $\left.30^{\circ} \mathrm{C}\right)$, but at $25^{\circ} \mathrm{C}$, M17 seemed to be most attractive to ORSU, and trapping rates reached about $65 \%$, while at under $20^{\circ} \mathrm{C}$ and $30{ }^{\circ} \mathrm{C}$, trapping rates of traps baited with M17 were about 21\% (Figure 3). The different trapping rates of food attractants at different temperatures may be due to beetle behaviors such foraging and crawling varying at different temperatures, and temperature can greatly impact the amount and speed of volatiles released from food attractants, factors that we were unable to exclude from our experiments. Previous reports have indicated that between $11^{\circ} \mathrm{C}$ and $35^{\circ} \mathrm{C}$, ORSU walking speed increases with increasing temperature [53]. [54] verified that at $2{ }^{\circ} \mathrm{C}$, emissions of total volatiles and specific monoterpenes, mainly limonene, but also linalool and $\alpha$-terpineol from star ruby red grapefruit were enhanced, while storage at 12 ${ }^{\circ} \mathrm{C}$ resulted in higher emissions and diversity of cyclic sesquiterpenes and aliphatic esters.

As well as the environmental temperature, the insect population density in the grain influenced the effectiveness of the traps baited with food attractants. At an insect density of 2.5 insects $/ \mathrm{kg}$, M17-baited traps reached their highest trapping rates of $58.10 \%$, however, interestingly, with an increase in insect density from $2.5 / \mathrm{kg}$ to $30 / \mathrm{kg}$, the trapping rate decreased (Figure $3 \mathrm{~A}$ ). A previous study demonstrated that insect population density profoundly affected the olfactory responses of $O$. surinamensis, and that low populations of beetles in culture (including when under starvation conditions) decreased the length of the refractory period to beetle and frass volatiles and advanced the onset of the period of positive olfactory response [55]. Moreover, the trapping percentages of pheromone traps have been found to increase with increasing T. castaneum population sizes, with the highest trapping percentage observed when beetles were released in population sizes 300, 350 
or 400 , and the lowest trapping percentage observed when the population size was 100 [56].

In this study, we tested the attractiveness of food mixtures not only in the laboratory, but also in a large, flat granary (Figure 4). Our data suggested that the food mixture M17 was the most attractive to ORSU, with the maximum trapping rate of $75.56 \%$, and that this mixture remained attractive for at least $40 \mathrm{~d}$. Low quantities (7.6 g) of M17 as well as larger amounts (to $100 \mathrm{~g}$ ), were able to trap insects (Figure 4C). We also found the attractiveness of both $1 \mathrm{~g}$ or $7.6 \mathrm{~g}$ of M17 was stronger than that of the commercial attractant Xlure MST trap after 21 days (Figure 2C) or 47 days (Figure 4B), respectively. The price of the food attractants tested here is much lower than that of the commercial product Xlure MST. Furthermore, the Xlure MST trap could attract more than one species of stored-product insects, and our food mixture M17 was also attractive to three (T. castaneum, C. ferrugineus, S. oryzae) of four tested insects (Figure 5A). We therefore believe that food mixture M17 has commercial potential and may be worth popularizing as a broad spectrum insect attractants, particularly once its attractiveness to further species of stored-product insect has been tested.

The behavioral and electrophysiological assays show that the volatiles from food mixtures may play an important role in the attractiveness of foods to insects (Figure 6-9). The air flowing over M17 attracted significantly more ORSU than did that flowing over the control, flour, or other three food mixtures (Figure 6). Furthermore, eluents of volatiles showed effective trapping activity (Figure 7A-C). [57] also reported that volatile compounds were a factor involved in location and selection of foods by Liposcelis bostrychophila when in proximity to a food. Insects, like many other animals, rely on chemical signals to find food and mates [58].

In general, insects are able to recognize volatile odors swiftly through their antennae. Using GC-EAD technology, we identified eight chemicals as potentially bioactive compounds in the volatile extracts of the food attractant. We were able to identify six of these chemicals as nonanal, dodicane, tridicane, $\beta$-caryophyllene, methyl ester, and dibutyl phthalate using GC-MS (Figure 8 and 9, Table 2). Interestingly, nonanal has been identified from both oatmeal [59] and brown sugar [59], and dibutyl phthalate has also been identified from brown sugar [60]. We found that $\beta$-caryophyllene prompted significant electrophysiological activity in the test antennae as well as ORSU behavior, and $\beta$-caryophyllene is well known as a chemical attractive to several insect species, including Trigonotylus caelestialium (Kirkaldy) (Heteroptera: Miridae) [61], and Asian honey bees (Apis cerana) [62]. However, only four of the six compounds isolated from the food volatiles in our experiment were able to elicit a significant antennal EAG response from ORSU, at a series of different chemical concentrations (Figure 9A). Moreover, not all compounds with significant EAG activity were attractive to the living ORSU insects. For example, dibutyl phthalate was no more attractive to the insewcts than the control (Figure 9A and B), and tridecane, which had no significant EAG activity compared to the control, showed apparent trap activity (Figure 9A and B). [63] investigated the GC-EAD responses of the antennae of the kudzu bug Megacopta cribraria (Hemiptera: Plataspidae). Six GC-EAD active compounds were identified from volatiles collected from undamaged potted plants, but the antennal responses of the bug, to farnesene and ocimene differed from the behavioral responses. Differences between antennal and behavioral responses also have been reported in Lygus hesperus Knight (Heteroptera: Miridae) [64], and Maruca vitrata Fabricius (Lepidoptera: Crambidae) [65]. Under natural conditions, insects are confronted with complex mixtures of compounds and their responses to these odor blends can only be evaluated in behavioral studies [66].

In our experiments, four chemicals, nonanal, dodecane, tridicane and $\beta$-caryophyllene were attractive to ORSU, while the attractiveness of the other two chemicals, methyl palmitate, and dibutyl phthalate, were low and may be detected as background odors. In many cases it appears that the volatile organic components of a target are not all always essential for attraction [67]. We infer that these two compounds may also be used 
as background odor substances to enhance the recognition of other important active compounds, or they perhaps play a role in the mixture [68,69]. However, we found that the background odors also have some role in the attractiveness of the food mixture, and that ORSU was able to more easily distinguish mixtures of all six compounds than of mixtures comprising fewer chemicals compared to the control (Figure 9D). [31] showed that adults of the stored-grain pest species Sitophilus granarius (L.) (Coleoptera: Curculionidae) were attracted by three compounds at lower concentrations, but that these chemicals acted as repellents at higher concentrations. They also mention that the adult beetles have the ability to respond behaviorally to a wide range of cereal volatiles, and that the responses may change as a function of the chemical concentration. Interestingly, the chemical mixtures of the six compounds we isolated from eluents of M17 volatiles did not attract ORSU at 100 times concentration more effectively than the control (Figure $9 \mathrm{C}$ ), but at 1 times concentration, this mixture worked well (Figure 9 D). Unlike Sitophilus granarius, which is able to respond effectively to the three test compounds at a wide range of concentrations, it is possible that ORSU may only be attracted to chemical mixtures at a narrow range of concentrations.

\section{Conclusions}

In conclusion, this study provides insight into the possibility that food mixtures could be developed as effective attractants and the volatiles used by stored-product insects to locate them also could be utilized as lures of chemical mixtures as one form of semiochemical-based management of ORSU. Moreover, the food volatiles may have potential as the basis for the development of semiochemical-based IPM approaches as well as pheromones for the control of stored-grain pests. The food mixtures or food volatiles may work as lures not only to control populations of stored-product insects, but also to monitor their population dynamics in a granary. Much remains to be studied in the field of interactions between stored-product insects, food based attractants and environmental factors such as temperature and humidity, but we believe that food-based attractants may have a future as one part of an IMP program in the effective control of stored-grain insects.

Supplementary Materials: The following are available online at www.mdpi.com/xxx/s1, Figure S1: Schematic diagram of insect trap. a, gape holes around the insect trap; b, plan of 50mL trap decvice; c, the top circle of gape holes around the trap is kept parallel to the surface of the grain, Figure S2: Diagram of attraction experiment in plastic frame. a, insect trap containing food mixtures; $b$, plastic frame; Figure S3: Schematic diagram of the commercial trap Xlure, Figure S4: Schematic diagram of volatile collection device. a, air pump; b, e, flowmeters; c, adsorption tube; d, collection bottle; $\mathrm{f}$, activated carbon. Figure S5: Schematic diagram of four-armed olfactometer.

Table S1: List of 38 kinds of foods. 


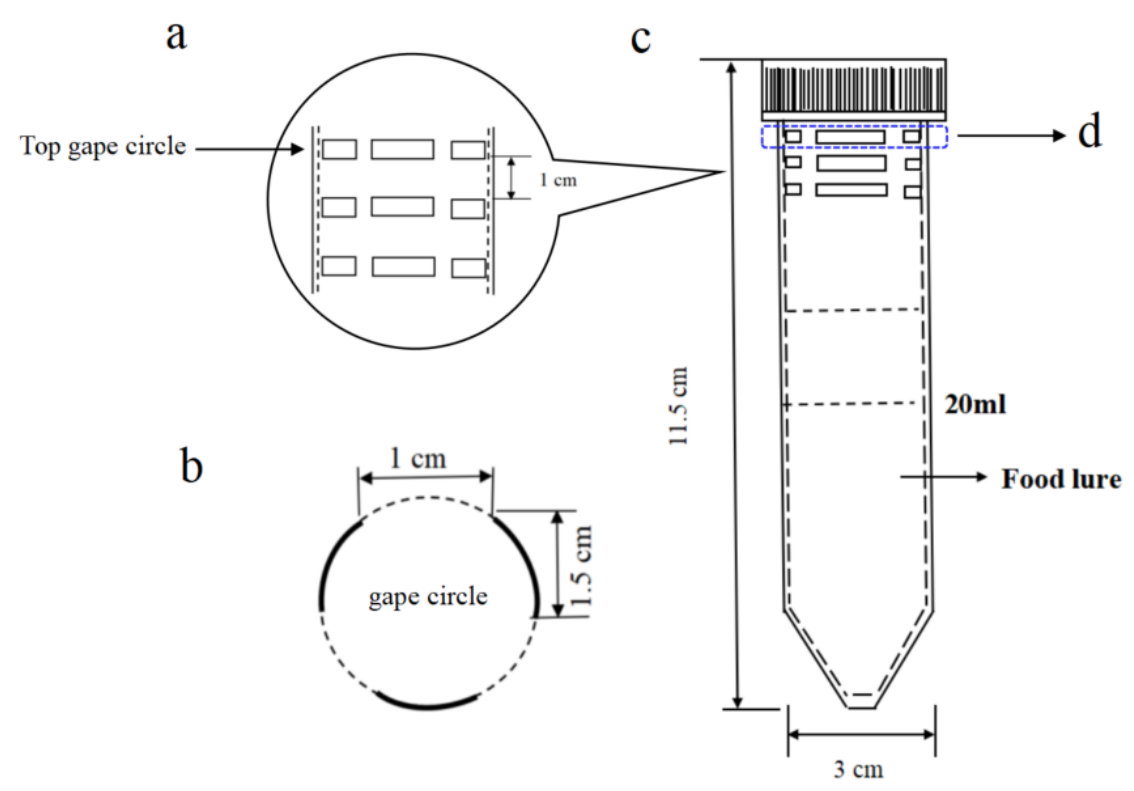

Figure S1 


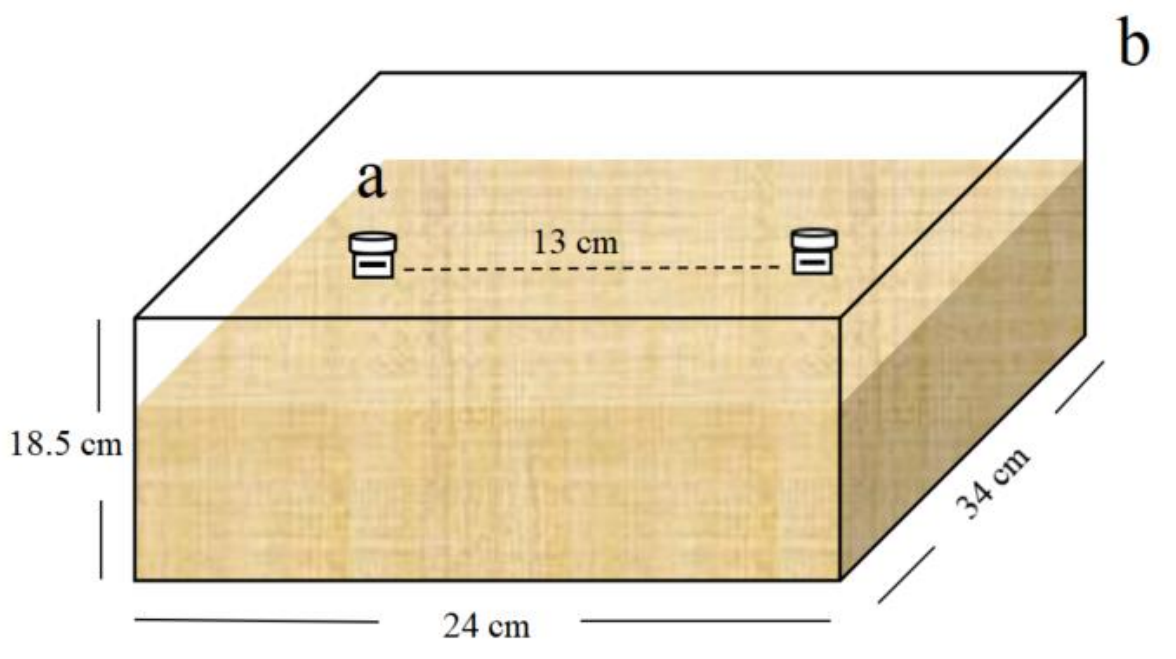

Figure S2 


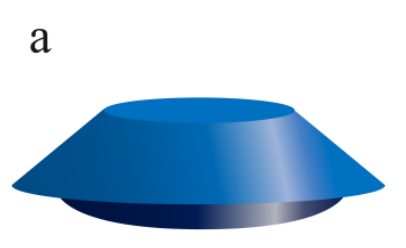

b

c

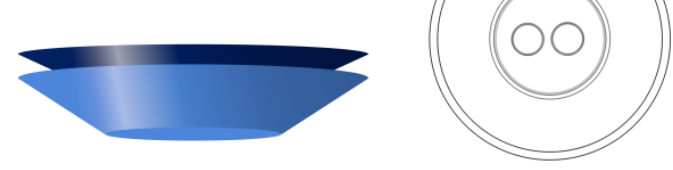

Figure S3 


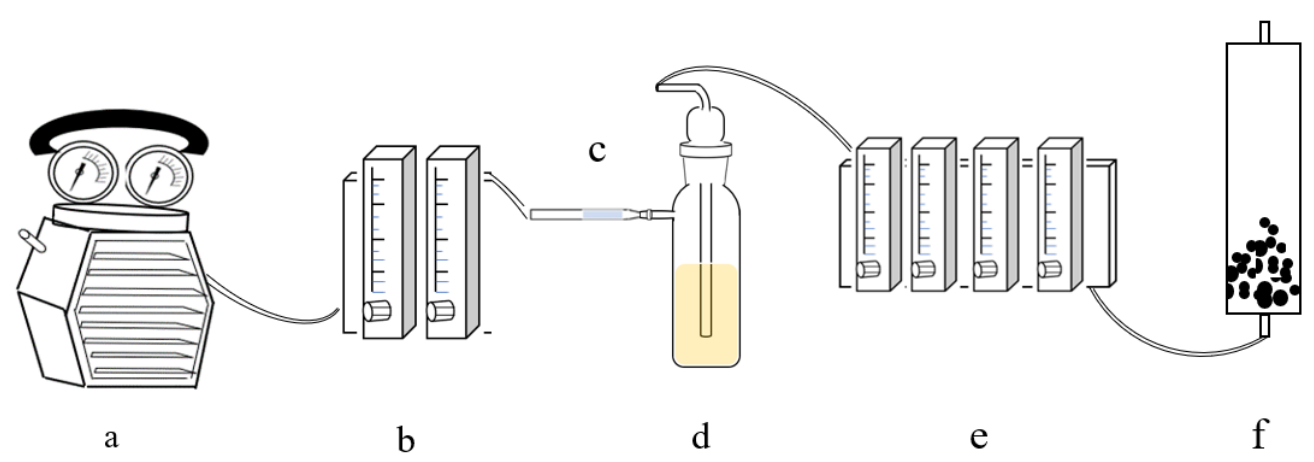

Figure S4 
a.

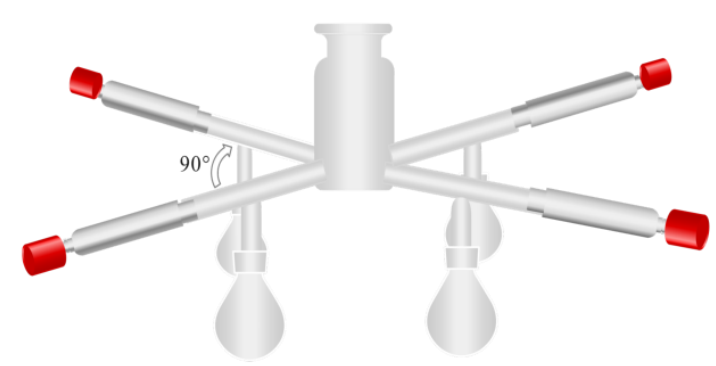

b.

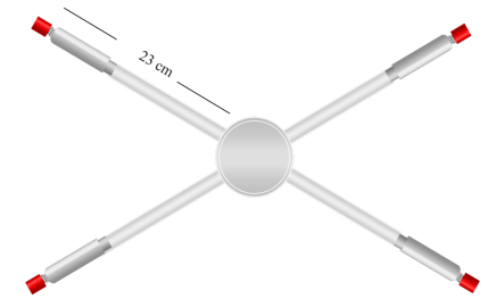

c.

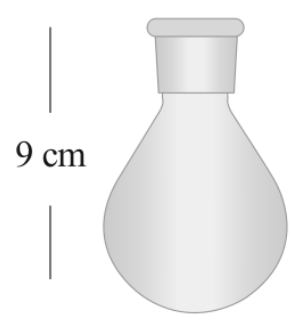

Figure S5 
Table S 1

\begin{tabular}{|c|c|c|}
\hline No. & Name of Food & Brand \\
\hline 1 & Oatmeal & QUAKER \\
\hline 2 & Dried figs & Su Xiang Ge \\
\hline 3 & Brown sugar & Tai gu \\
\hline 4 & Dried hawthorn fruits & HuaWeiHeng \\
\hline 5 & Cashew nuts & Xinhuo \\
\hline 6 & Millet & Zhongyue \\
\hline 7 & Dried wolfberry & Fengkaiyuanshiye \\
\hline 8 & Steel-cut corn germ & Quhou \\
\hline 9 & Kiwi fruit slices & Baicaowei \\
\hline 10 & Dried red dates & Xinbianjie \\
\hline 11 & Sesame seeds & Baizuan \\
\hline 12 & Breadcrumbs & Xinliang \\
\hline 13 & Groundnuts & Shanggong \\
\hline 14 & Mung beans & Quhou \\
\hline 15 & Orchid beans & Baicaowei \\
\hline 16 & Dried grapes & Baicaowei \\
\hline 17 & Black raisins & Grape king \\
\hline 18 & Fried soybeans & Kanglilai \\
\hline 19 & Potato starch & Haiyue \\
\hline 20 & Caramel sweets & Xufuji \\
\hline 21 & Cornstarch & Zhanyi \\
\hline 22 & Almonds & Zhanyi \\
\hline 23 & Pine nuts & Haodi \\
\hline 24 & Pistachios & Baicaowei \\
\hline 25 & Brown rice & Quhou \\
\hline 26 & Edible salt & Yanye \\
\hline 27 & Walnuts & Taoyuan \\
\hline 28 & Aginomoto & Taitaile \\
\hline 29 & Dried bananas & Baicaowei \\
\hline 30 & Biscuits & Qingshi \\
\hline 31 & Wafers & Gaizhi \\
\hline 32 & Pecans & Baicaowei \\
\hline 33 & Soybean powder & Kaerdai \\
\hline 34 & Ormosia beans & Quhou \\
\hline 35 & Bread & Mankattan \\
\hline 36 & Cane sugar & Taigu \\
\hline 37 & Chocolate & Dove \\
\hline 38 & Dried yeast & Angel Yeast Co. LTD \\
\hline
\end{tabular}


Author Contributions: Conceptualization, G.X.Z., X.Q.L., and M.S.; field methodology, M.S.,L.J., B.S.; validation, M.S., Z.H.L and Z.J.W.; investigation, J.R.W., J.Y.D.; writing - review and editing, M.S., J.R.W., X.W., and G.X.Z. project administration and funding acquisition, G.X.Z., and X.Q.L. All authors have read and agreed to the published version of the manuscript.

Funding: The project leading to these results was supported by the National key Research and Development Program (2018YFD0401403), Key Research and Development Plan of Zhejiang Province (2018C02050), the National Natural Science Foundation of China (31572020, 32072508), Natural Science Foundation of Zhejiang Province (LY19C140005), the Shaoxing Key Research and Development Plan (2017A22004), and the Science Foundation of Zhongsui Industrial Limited Company in Zhejiang Province, China (Cangchubu2018-001).

Acknowledgments: We thank Zeyu Zhang and Xiaocui Huang for technical assistance and Ted C. J. Turlings (Institute of Biology, Unversity Neuchatel, Switzerland) for revising this manuscript sincerely. We also thank anonymous reviewers for their critical reviews and helpful feedback on the manuscript.

Conflicts of Interest: The authors declare no conflict of interest.

\section{References}

1. Morrison, W.; Bruce, A.; Wilkins, R.; Albin, C.; Arthur, F. Sanitation improves stored product insect pest management. Insects 2019, 10, 1-20.

2. Nayak, M.K.; Daglish, G.J. Importance of stored product insects. Springer: Berlin, Germany, 2018; pp.1-273, ISBN 9783-662-56123-2.

3. Hagstrum, D.W.; Phillips, T.W. Evolution of stored-product entomology: protecting the world food supply. Annu. Rev. Entomol. 2017, 62, 379-397.

4. Jacobson, M. Plants, insects, and man - their interrelationships. Econ. Bot. 1982, 36, 346-354.

5. Phillips, T.W.; Throne, J.E. Biorational approaches to managing stored-product insects. Annu. Rev. Entomol. 2010, 55, 375-397.

6. Fields, P.G.; White, N.D.G. Alternatives to methyl bromide treatments for stored-product and quarantine insects. Annu. Rev. Entomol. 2002, 47, 331-359.

7. Nayak, M.K.; Daglish, G.J.; Phillips, T.W.; Ebert, P.R. Resistance to the fumigant phosphine and its management in insect pests of stored products: a global perspective. Annu. Rev. Entomol. 2020, 65, 333-350.

8. Kljajić, P.; Perić, I. Susceptibility to contact insecticides of granary weevil Sitophilus granarius (L.) (Coleoptera: Curculionidae) originating from different locations in the former Yugoslavia. J. Stored Prod. Res. 2006, 42, 149-161.

9. Daglish, G.J. Effect of exposure period on degree of dominance of phosphine resistance in adults of Rhyzopertha dominica (Coleoptera: Bostrychidae) and Sitophilus oryzae (Coleoptera: Curculionidae). Pest Manag. Sci. 2004, 60, $822-826$.

10. Nayak, M.K.; Holloway, J.C.; Emery, R.N.; Pavic, H.; Bartlet, J.; Collins, P.J. Strong resistance to phosphine in the rusty grain beetle,Cryptolestes ferrugineus (Stephens) (Coleoptera: Laemophloeidae): its characterisation, a rapid assay for diagnosis and its distribution in Australia. Pest Manag. Sci. 2013, 69, 48-53.

11. Pimentel, M.A.G.; Faroni, L.R.D.; Tótola, M.R.; Guedes, R.N.C. Phosphine resistance, respiration rate and fitness consequences in stored-product insects. Pest Manag. Sci. 2007, 63, 876-881.

12. Opit, G.P.; Phillips, T.W.; Aikins, M.J.; Hasan, M.M. Phosphine resistance in Tribolium castaneum and Rhyzopertha dominica from stored wheat in Oklahoma. J. Econ. Entomol. 2012, 105, 1107-1114.

13. Gautam, S.G.; Opit, G.P.; Konemann, C.; Shakya, K.; Hosoda, E. Phosphine resistance in saw-toothed grain beetle Oryzaephilus surinamensis in the United States. J. Stored Prod. Res. 2020, 89, 1-8. 
14. Rajkumar, V.; Gunasekaran, C.; Christy, I.K.; Dharmaraj, J.; Chinnaraj, P.; Paul, C.A. Toxicity, antifeedant and biochemical efficacy of Mentha piperita L. essential oil and their major constituents against stored grain pest. Pestic. Biochem. Phys. 2019.

15. Hamel, D.; Rozman, V.; Liška, A. Storage of cereals in warehouses with or without Pesticides. Insects 2020, $11,846$.

16. Bergvinson, D.; Lara, S.G. Genetic approaches to reducing losses of stored grain to insects and diseases. Curr. Opin. Plant Biol. 2004, 7, 480-485.

17. Morrison, W.R.; Scully, E.D.; Campbell, J.F. Towards developing areawide semiochemical - mediated, behaviorally - based integrated pest management programs for stored product insects. Pest Manag. Sci. 2021, 1-16.

18. Chambers, J. Overview on stored-product insect pheromones and food attractants. Journal of the Kansas Entomological Society 1990, 63, 490-499.

19. Justiniano, W.; Fernandes, M.G. Effect of food attractants and insecticide toxicity for the control of Spodoptera frugiperda (Lepidoptera: Noctuidae) adults. J. Agr. Sci. 2020, 12, 129-137.

20. Majid, A.H.A.; Dieng, H.; Ellias, S.S.; Sabtu, F.S.; Rahim, A.H.A.; Satho, T. Olfactory behavior and response of household ants (Hymenoptera) to different types of coffee odor: a coffee-based bait development prospect. J. AsiaPac. Entomol. 2018, 21, 46-51.

21. Trematerra, P.; Athanassiou, C.; Stejskal, V.; Sciarretta., A.; Kavallieratos, N.; Palyvos, N. Large-scale mating disruption of Ephestia spp. and Plodia interpunctella in Czech republic, Greece and Italy. J. Appl. Entomol. 2011, 135, $749-762$.

22. Castro, P.F.; González-Hernández, H.; Carrillo-Sánchez, J.L.; Solís-Aguilar, J.F.; José, I.D.R.; Rubio-Cortés, R.; Rojas, J.C. Amount and bagging of the bait food affect the captures of Scyphophorus acupunctatus (Coleoptera: Curculionidae) by pheromone-baited traps. Fla. Entomol. 2018, 101, 6-11.

23. Freedman, B.; Mikolajczak, K.L.; Smith Jr, C.R.; Kwolek, W.F.; Burkholoer, W.E. Olfactory and aggregation responses of Oryzaephilus Surinamensis (L.) to extracts from oats. J. Stored Prod. Res. 1982, 18, 75-82.

24. Trematerra, P.; Sciarreta, A.; Tamasi, E. Behavioural responses of Oryzaephilus surinamensis, Tribolium castaneum and Tribolium confusum to naturally and artificially damaged durum wheat kernels. Entomol. Exp. Appl. 2000, 94 , 195 200.

25. Hori, M.; Miwa, M.; Iizawa, H. Host suitability of various stored food products for the cigarette beetle, Lasioderma serricorne (Coleoptera: Anobiidae). Appl. Entomol. Zool. 2011, 46, 463-469.

26. Rajendran, S. Insect pest management in stored products. Outlooks on Pest Management 2020, 31, 24-35.

27. Dissanayaka, D.M.S.K.; Sammani, A.M.P.; Wijayaratne, L.K.W. Food oils as kairomones for trapping Tribolium castaneum (Herbst) (Coleoptera: Tenebrionidae) adults. J. Stored Prod. Res. 2018, 79, 83-88.

28. Hagstrum, D.W.; Phillips, T.W.; Cuperus, G. Stored product protection. Kansas State University: Kansas State, USA, 2012; pp.1-350, ISBN 978-0-9855003-0-6.

29. Pierce, A.M.; Broden, J.H.; Oehlschlager, A.C. Olfactory response to beetle-produced volatiles and host-food attractants by Oryzaephilus surinamensis and O. mercator. Journal Canadien de Zoologie 1981, 59, 1980-1990.

30. Pierce, A.M.; PierceJr, H.D.; Oehlschlager, A.C.; Borden, J.H. Attraction of Oryzaephilus surinamensis (L.) and Oryzaephilus mercator (Fauvel) (Coleoptera: Cucujidae) to some common volatiles of food. J. Chem. Ecol. 1990, 16, 46575.

31. Germinara, G.S.; De Cristofaro, A.; Rotundo, G. Behavioral responses of adult Sitophilus granarius to individual cereal volatiles. J. Chem. Ecol. 2008, 34, 523-529.

32. Wakefield, M.E.; Bryning, G.P.; Chambers, J. Progress towards a lure to attract three stored product weevils, Sitophilus zeamais Motschulsky, S. oryzae (L.) and S. granarius (L.) (Coleoptera: Curculionidae). J. Stored Prod. Res. 2005, $41,145-161$. 
33. Lorenzo, M.G.; Manrique, G.; Pires, H.H.R.; Brito Sánchez, M.G.D.; Diotaiuti, L.; Lazzari, C.R. Yeast culture volatiles as attractants for Rhodnius prolixus: electroantennogram responses and captures in yeast-baited traps. Acta Trop. 1999, 72, 119-124.

34. Olsson, P.O.C.; Anderbrant, O.; Löfstedt, C. Flight and oviposition behavior of Ephestia cautella and Plodia interpunctella in response to odors of different chocolate products. J. Insect Behav. 2005, 18, 363-380.

35. Sidney, M.; Gries, R.; Danci, A.; Judd, G.J.R.; Gries, G. Almond volatiles attract neonate larvae of Anarsia lineatella (Zeller) (Lepidoptera: Gelechiidae). Journal of the Entomological Society of British Columbia 2006, 3-10.

36. Noge, K. Hexanal, a major volatile found in fresh peanut seed, elicits foraging behavior in the laboratory-reared brown marmorated stink bug, Halyomorpha halys (Heteroptera: Pentatomidae). J. Pestic. Sci. 2019, 44, 15-19.

37. Mahmood, R.K. Effect of some plant powders on aspects of the biological performance for sawtoothed grain beetle Oryzaephilus surinamensis L. (Coleoptera: Silvanidae). Plant Archives 2019, 19, 1378-1381.

38. Nika, E.P.; Kavallieratos, N.G.; Papanikolaou, N.E. Developmental and reproductive biology of Oryzaephilus surinamensis (L.) (Coleoptera: Silvanidae) on seven commodities. J. Stored Prod. Res. 2020, 87, 1-6.

39. Boxall, R.A. Post-harvest losses to insects - a world overview. Int. Biodeter. Biodegr. 2001, 48, $137-152$.

40. Wang, Z.; Xie, Y.; Sabier, M.; Zhang, T.; Deng, J.; Song, X.; Liao, Z.; Li, Q.; Yang, S.; Cao, Y.; Liu, X.; Zhou, G. Transanethole is a potent toxic fumigant that partially inhibits rusty grain beetle (Cryptolestes ferrugineus) acetylcholinesterase activity. Ind. Crop. Prod. 2021, 161, 1-13.

41. Xu, H.; Zhou, G.; Dötterl, S.; Schäffler, I.; Degen, T.; Chen, L.; Turlings, T.C.J. Distinct roles of Cuticular Aldehydes as pheromonal cues in two Cotesia parasitoids. J. Chem. Ecol. 2020, 46, 128-137.

42. Mcllroy, J.W.; Jones, A.D.; Mcguffin, V.L. Gas chromatographic retention index as a basis for predicting evaporation rates of complex mixtures. Anal. Chim. Acta 2014, 852, 257-266.

43. Ning, T.; Fan, J.T.; Fang, Y.L.; Sun, J.H. Changes in contents of host volatile terpenes under different damaged states and electroantennogram response of Monochamus alternatus Hope to these volatiles. Acta Entomologica Sinica , 2006, $179-188$.

44. Tang, Q.; Zhang, C. Data processing system (DPS) software with experimental design, statistical analysis and data mining developed for use in entomological research. Insect Sci. 2013, 20, 254-260.

45. Hanna, R.; Gnanvossou, D.; Goergen, G.; Bokonon-Ganta, A.H.; Mohamed, S.A.; Ekesi, S.; Fiaboe, K.K.M.; Agnontchémè, A.I. Efficiency of food-based attractants for monitoring Tephritid fruit flies diversity and abundance in Mango systems across three west African agro-ecological zones. J. Econ. Entomol. 2020, 113, 860-871.

46. Huang, J.; Gut, L.; Grieshop, M. Evaluation of food-based attractants for Drosophila suzukii (Diptera: Drosophilidae). Environ. Entomol. 2017, 46, 878-884.

47. Shelly, T.; Kurashima, R.; Fezza, T. Field evaluation of three-component solid food-based dispenser versus torula yeast for capturing Mediterranean and Oriental fruit flies (Diptera: Tephritidae). J. Asia-Pac. Entomol. $2020,23$.

48. Wang, C.L.; Bennett, G.W. Comparison of Cockroach traps and attractants for monitoring German Cockroaches (Dictyoptera: Blattellidae). Environ. Entomol. 2006, 35, 765-770.

49. Phoonan, W.; Deowanish, S.; Chavasiri, W. Food attractant from mulberry leaf tea and its main volatile compounds for the biocontrol of Lasioderma serricorne F. (Coleoptera: Anobiidae). J. Stored Prod. Res. 2014, 59, $299-305$.

50. Hao, G.H.; Zeng, L.; Zeng, L. Olfactory response of Cryptolestes turcicus (Grouvelle) to six varieties of grain, 11th International Working Conference on Stored Product Protection, Chiang Mai, Thailand, 24-28 November 2014; pp.152-157.

51. Olsson, P.O.C.; Anderbrant, O.; Löfstedt, C.; Borg-Karlson, A.; Liblikas, I. Electrophysiological and behavioral responses to chocolate volatiles in both sexes of the pyralid moths Ephestia cautella and Plodia interpunctella. J. Chem. Ecol. 2005, 31, 2947-2961. 
52. Ileleji, K.E.; Maier, D.E.; Woloshuk, C.P. Evaluation of different temperature management strategies for suppression of Sitophilus zeamais (Motschulsky) in stored maize. J. Stored Prod. Res. 2007, 43, 480-488.

53. Wang, D.X.; An, C.N.; Li, Z.D.; Lian, G.R. Influence of temperature on moving and distribution of Oryzaephilus surinamensis (Linnaeus) adults on flat surface and in vertical wheat column. Journal of Henan Agricultural University 2013, 47, 330-333,367.

54. Lado, J.; Gurrea, A.; Zacarías, L.; Rodrigo, M.J. Influence of the storage temperature on volatile emission, carotenoid content and chilling injury development in star ruby red grapefruit. Food Chem. 2019, 295, 1-36.

55. Pierce, A.M.; Borden, J.H.; Oehlschlager, A.C. Effects of age and population density on response to beetle and food volatiles by Oryzaephilus surinamensis and O. mercator (Coleoptera: Cucujidae). Environ. Entomol. 1983, 12, 13671374.

56. Dissanayaka, D.M.S.K.; Sammani, A.M.P.; Wijayaratne, L.K.W. Response of different population sizes to traps and effect of spinosad on the trap catch and progeny adult emergence in Tribolium castaneum (Herbst) (Coleoptera: Tenebrionidae). J. Stored Prod. Res. 2020, 86, 1-8.

57. Green, P.W.C.; Turner, B.D. Food-selection by the booklouse, Liposcelis bostrychophila Badonnel (Psocoptera: Liposcelididae). J. Stored Prod. Res. 2005, 41, 103-113.

58. Witzgall, P.; Stelinski, L.; Gut, L.; Thomson, D. Codling moth management and chemical ecology. Annu. Rev. Entomol. 2008, 53, 503-522.

59. Cognat, C.; Shepherd, T.; Verrall, S.R.; Stewart, D. Comparison of two headspace sampling techniques for the analysis of off-flavour volatiles from oat based products. Food Chem. 2012, 134, 1592-1600.

60. Chen, E.; Song, H.; Chen, E.; Liu, C.; Tang, L.; Zhang, Y. Comparison of odor compounds of brown sugar, muscovado sugar, and brown granulated sugar using GC-O-MS. Food Sciene and Technology 2021, 142, 1-15.

61. Hori, M.; Enya, S. Attractiveness of synthetic volatile blends of flowering rice panicles to Trigonotylus caelestialium (Kirkaldy) (Heteroptera: Miridae). J. Appl. Entomol. 2013, 137, 97-103.

62. Zhang, X.M. Floral volatile sesquiterpenes of Elsholtzia rugulosa (Lamiaceae) selectively attract Asian honey bees. J. Appl. Entomol. 2018, 142, 359-362.

63. Yang, L.; Hu, X.P.; Allan, S.A.; Alborn, H.T.; Bernier, U.R. Electrophysiological and behavioral responses of the Kudzu Bug, Megacopta cribraria (Hemiptera: Plataspidae), to volatile compounds from Kudzu and soybean plants. J Agric Food Chem 2019, 67, 4177-4183.

64. Williams, L.; Blackmer, J.L.; Rodriguez-Saona, C.; Zhu, S. Plant volatiles influence electrophysiological and behavioral responses of Lygus hesperus. J. Chem. Ecol. 2010, 36, 467-478.

65. Wang, P.; Zhang, N.; Zhou, L.; Si, S.; Lei, C.; Ai, H.; Wang, X. Antennal and behavioral responses of female Maruca vitrata to the floral volatiles of Vigna unguiculata and Lablab purpureus. Entomol. Exp. Appl. 2014, 152, $248-257$.

66. Weissbecker, B.; Loon, J.J.A.V.; Posthumus, M.A.; Bouwmeester, H.J.; Dicke, M.; Wageningen, U.N.L.O. Identification of volatile potato sesquiterpenoids and their olfactory detection by the two-spotted stinkbug Perillus bioculatus. J. Chem. Ecol. 2000, 26, 1433-1445.

67. Biasazin, T.D.; Karlsson, M.F.; Hillbur, Y.; Seyoum, E.; Dekker, T. Identification of host blends that attract the African invasive fruit fly, Bactrocera invadens. J. Chem. Ecol. 2014, 40, 966-976.

68. Mccormick, A.C.; Unsicker, S.B.; Gershenzon, J. The specificity of herbivore-induced plant volatiles in attracting herbivore enemies. Trends Plant Sci. 2012, 17, 303-310.

69. Wijk, M.V.; Bruijn, P.J.A.; Sabelis, M.W. Complex odour from plants under attack: herbivore's enemies react to the whole, not its parts. PLoS One 2011, 6, 1-7. 